Chapman University

Chapman University Digital Commons

Mathematics, Physics, and Computer Science

Faculty Articles and Research

Science and Technology Faculty Articles and

Research

$5-11-2020$

\title{
Synergistic Use of Remote Sensing and Modeling for Estimating \\ Net Primary Productivity in the Red Sea With VGPM, Eppley- \\ VGPM, and CbPM Models Intercomparison
}

Wenzhao Li

Surya Prakash Tiwari

Hesham el-Askary

Mohamed Ali Qurban

Vassilis Amiridis

See next page for additional authors

Follow this and additional works at: https://digitalcommons.chapman.edu/scs_articles

Part of the Atmospheric Sciences Commons, Climate Commons, Environmental Chemistry Commons, Environmental Health and Protection Commons, Environmental Indicators and Impact Assessment

Commons, Environmental Monitoring Commons, Numerical Analysis and Scientific Computing Commons, Oceanography Commons, Other Computer Sciences Commons, Other Environmental Sciences Commons, Physical and Environmental Geography Commons, and the Remote Sensing Commons 


\section{Synergistic Use of Remote Sensing and Modeling for Estimating Net Primary Productivity in the Red Sea With VGPM, Eppley-VGPM, and CbPM Models Intercomparison}

\section{Comments}

This is a pre-copy-editing, author-produced PDF of an article accepted for publication in IEEE Transactions on Geoscience and Remote Sensing in 2020 following peer review. The definitive publisher-authenticated version is available online at https://doi.org/10.1109/TGRS.2020.2990373.

\section{Copyright}

(C) 2020 IEEE. Personal use of this material is permitted. Permission from IEEE must be obtained for all other uses, in any current or future media, including reprinting/republishing this material for advertising or promotional purposes, creating new collective works, for resale or redistribution to servers or lists, or reuse of any copyrighted component of this work in other works.

\section{Authors}

Wenzhao Li, Surya Prakash Tiwari, Hesham el-Askary, Mohamed Ali Qurban, Vassilis Amiridis, K. P. Manikandan, Michael J. Garay, Olga V. Kalashnikova, Thomas C. Piechota, and Daniele C. Struppa 


\title{
Synergistic use of Remote Sensing and Modeling for Estimating Net Primary Productivity in the Red Sea with VGPM, Eppley-VGPM and CbPM models Intercomparison
}

\author{
Wenzhao Li, Surya P. Tiwari, Hesham M. El-Askary, Member, IEEE, Mohamed A. Qurban, Vassilis \\ Amiridis, K. P. ManiKandan, Michael J. Garay, Olga V. Kalashnikova, Thomas Piechota and Daniele
} Struppa

\begin{abstract}
Primary Productivity (PP) has been recently investigated using remote sensing based models over quite limited geographical areas of the Red Sea. This work sheds light on how phytoplankton and primary production would react to the effects of global warming in the extreme environment of the Red Sea and, hence, illuminates how similar regions may behave in the context of climate variability. Our study focuses on using satellite observations to conduct an intercomparison of three net primary production (NPP) models - the VGPM (Vertically Generalized Production Model), the Eppley-VGPM and the CbPM (Carbonbased Production Model) - produced over the Red Sea domain for the 1998-2018 time period. A detailed investigation is conducted using multilinear regression analysis, multivariate visualization and moving averages correlative analysis to uncover the models' responses to various climate factors. Here we use the models' 8day composite and monthly averages compared with satellitebased variables including chlorophyll-a (Chla), mixed layer depth (MLD) and sea surface temperature (SST). Seasonal anomalies of NPP are analyzed against different climate indices, namely, the North Pacific Gyre Oscillation (NPGO), the Multivariate ENSO Index (MEI), the Pacific Decadal Oscillation (PDO), the North Atlantic Oscillation (NAO) and the Dipole Mode Index (DMI). In our study, only the CbPM showed significant correlations with NPGO, MEI and PDO, with disagreements relative to the other two NPP models. This can be attributed to the models' connection to oceanographic and atmospheric parameters, as well as the
\end{abstract}

Manuscript received. (Corresponding author: Hesham Mohamed ElAskary.)

Wenzhao Li is with the Schmid College of Science and Technology, Chapman University, Orange, CA 98266 USA (e-mail: 1i276@mail.chapman.edu).

Surya P. Tiwari, Mohamed A. Qurban and K. P. ManiKandan are with Center for Environment and Water, The Research Institute, King Fahd University of Petroleum and Minerals (KFUPM), Dhahran, 31261, Kingdom of Saudi Arabia. Mohamed A. Qurban is also with Geosciences Department, the college of Petroleum Engineering \& Geosciences, King Fahd University of Petroleum and Minerals (KFUPM). (e-mail: surya.tiwari@kfupm.edu.sa; mqurban@kfupm.edu.sa; manikand@kfupm.edu.sa)

H. M. El-Askary is with the Schmid College of Science and Technology, Chapman University, Orange, CA 98266 USA, Center of Excellence in Earth Systems Modeling \& Observations, Chapman University, Orange, CA 92866 trends in the southern Red Sea, thus calling for a further validation efforts.

Index Terms - Primary production, remote sensing, ocean color, Red Sea, VGPM, Eppley-VGPM, CbPM, climate indices.

\section{INTRODUCTION}

$\mathrm{M}$ arine primary productivity is the rate at which photosynthetic organisms (mainly phytoplankton) produce organic compounds in the marine ecosystem. The net primary productivity (NPP) is considered as the main indicator of the biogeochemical cycle since nearly half of the global photosynthetically fixed carbon is derived from ocean phytoplankton [1], [2]. Therefore, accurate estimation of NPP is of great interest in the assessment and studies of fisheries source management, marine ecology systems and climate processes [3]. However, traditional ship-based in situ measurements are limited in their ability to capture the largescale spatial and temporal dynamics of NPP, and are time consuming and expensive [4], [5]. Fortunately, satellite-borne sensors can address these shortcomings through their routine observations of the dynamics of the ocean surface, providing fundamental means for estimating oceanic NPP on large spatiotemporal scales [6]-[9]. Such observations help in

USA, and also with the Department of Environmental Sciences, Faculty of Science, Alexandria University, Alexandria 21522, Egypt (e-mail: elaskary@chapman.edu).

Vassilis Amiridis is with IAASARS, National Observatory of Athens, 15236 Athens, Greece (e-mail: vamoir@noa.gr).

M. J. Garay and O. V. Kalashnikova are with the Jet Propulsion Laboratory, California Institute of Technology, Pasadena, CA 91109 USA (e-mail: Michael.J.Garay@jpl.nasa.gov; olga.kalashnikova@jpl.nasa.gov).

Thomas Piechota and Daniele Struppa are with Schmid College of Science and Technology, Chapman University, Orange, 92866, California, USA (email: piechota@chapman.edu; struppa@chapman.edu). 
accurately assessing the PP, which quantifies the amount of fixed carbon from photosynthesis, processes [10]. Many satellite-based NPP models have been proposed in recent years and are categorized by type as i) chlorophyll-based, ii) carbonbased and iii) phytoplankton absorption-based models [11] that will be further discussed in section II.B; or according to their complexities as i) wavelength resolved (WR), ii) depth resolved (DR), iii) wavelength integrated (WI), iv) time integrated (TI) and v) depth integrated (DI) [12]-[22]. These models have undergone extensive validation and accuracy assessment, through campaigns such as the Primary Productivity Algorithm Round Robin (PPARR), resulting in usage and conversion of remotely sensed environmental variables into PP [4], [15], [23]-[26]. Consequently it was found that the NPP data estimated from satellite based methods failed to show the seasonal variabilities and temporal trends in selected tropical regions (e.g., the tropical Pacific) [23], and underestimated the total PP [26]; moreover complex NPP models did not improve NPP estimates relative to simpler models [15].

Compared to other tropical regions, fewer studies exist that estimate PP for the Red Sea, and those that exist cover limited areas [27]. This is partly due to scarcity of oceanographic data because of the few surveys conducted in the waters of the Red Sea, although its marine resources are shared by eight countries (Saudi Arabia, Egypt, Sudan, Eritrea, Yemen, Israel, Jordan and Djibouti, in order of area of territorial waters). The extreme paucity of in situ data highlights the need for better estimates of PP in the Red Sea environment. Previous work from the King Fahd University of Petroleum and Minerals (KFUPM) undertook several multidisciplinary cruises in the Red Sea measuring physical and chemical parameters that could impact the PP in Saudi Arabian waters [27]-[31].

The Red Sea is a narrow, marginal oceanic basin in the northwest Indian Ocean. This basin extends from the Straits of $\mathrm{Bab}$ al Mandeb at $12.5^{\circ} \mathrm{N}$ in the south and branches off to $30^{\circ} \mathrm{N}$ in the Gulf of Aqaba (Eilat) to the northeast and the Gulf of Suez to the northwest. The Red Sea is $2250 \mathrm{~km}$ in length and $355 \mathrm{~km}$ in maximum width [32], [33]. Its seawater volume is approximately $233,000 \mathrm{~km} 3$, occupying an area of $4.51 \times 10$ 5 $\mathrm{km} 2$ with a maximum depth of $3040 \mathrm{~m}$ and an average depth of $490 \mathrm{~m}$ [27]. The Red Sea has the highest salinity of any major tropical oceanic basin due to its lack of river inflow, low precipitation rate $(<100 \mathrm{~mm} /$ year $)$ [34], [35] and high evaporation rate $(>210 \mathrm{~cm} /$ year) [36]. Because of its high salinity and temperature, the Red Sea becomes a natural laboratory to examine the responses of phytoplankton and coral reefs to the impacts of climate change [37]-[40]. The Red Sea can be conveniently divided into four major geographic regions [39], [41]. From north to south these are designated the Northern Red Sea (NRS) $\left(28^{\circ} \mathrm{N}\right.$ to $\left.24^{\circ} \mathrm{N}\right)$, the North Central Red Sea (NCRS) $\left(24^{\circ} \mathrm{N}\right.$ to $\left.20^{\circ} \mathrm{N}\right)$, the South Central Red Sea (SCRS) $\left(20^{\circ} \mathrm{N}\right.$ to $\left.17^{\circ} \mathrm{N}\right)$, and the Southern Red Sea (SRS) $\left(17^{\circ} \mathrm{N}\right.$ to $\left.13^{\circ} \mathrm{N}\right)$ (Fig. 1)

The Red Sea is characterized by meridional circulation, which involves the southward flow of dense waters from the northern basin along the basin bottom to the Gulf of Aden (GA), as well as compensatory flow from GA into the Red Sea, which includes the movement of subsurface Gulf of Aden Intermediate Water (GAIW) for part of the year (summerautumn) and surface waters for the rest (winter-spring) [32]. Traditionally, the Red Sea is defined as an oligotrophic water body with surface chlorophyll-a (Chla) $<2.6 \mathrm{mg} / \mathrm{m} 3$ with an increasing north-south gradient [36], [42]. However, recent studies showed the Red Sea's biomass and PP are significantly influenced by eddy activities [43]. These eddies bring nutrient rich subsurface GAIW to the surface, stimulating notable phytoplankton blooms. In addition, the phytoplankton diversity in the Red Sea is quite high with at least 463 identified phytoplankton species [27]. Therefore, the notion of low levels of PP in the oligotrophic waters of the Red Sea needs to be reconsidered.

For example, over six million tons of dust deposit into the Red Sea every year [27]. Summer dust storms are common along both coastlines, carrying phytoplankton-needed nutrients to the oligotrophic waters in the NRS and NCRS. However, frequent dust storms also block satellite observations of large areas of the SCRS and SRS [39], [41], resulting in limited availability of ocean color data for NPP modelling, especially from late boreal spring to early fall. Additionally, large and unevenly distributed dust has an effect on the energy balance of the Red Sea. This asymmetric effect may exert a significant influence on the regional atmospheric and oceanic circulations [44] and may impact the PP.

In this study we evaluated the performance of three different global NPP models in the Red Sea region namely, the Vertically Generalized Production Model (VGPM), the Eppley-VGPM (abbr. as Eppley) and the Carbon-based Productivity Model (CbPM) [13], [22], [45], to understand the PP as well as PP regulating factors and trends. Although having in-situ measurements for quantifying the models' skill is ultimately desired. However, model inter-comparison still allows us to identify either the environmental conditions or the different satellite derived parameters contributing to the models' different results and divergence.

\section{BACKGROUND}

\section{A. Study region}

In this study, we address the NPP estimation over different regions of the Red Sea. For each region, 16 sample points were used to collect different parameters, represented by identical colors (red: NRS, green: NCRS, blue: SCRS, olive: SRS) (Fig. 1). The performance of ocean color NPP models in deeper waters $(>250 \mathrm{~m})$ was significantly better, because these models were more challenged in coastal Case- 2 waters than open Case1 waters [20]. The influence of local-scale variability can be minimized by selecting data over the Red Sea and omitting coastal Case- 2 waters where suspended inorganic particle loads can be particularly high [13]. Therefore, the samples were selected based on their location and water column depths (> 600 $\mathrm{m})$, assuming these areas represent Case-1 waters. 


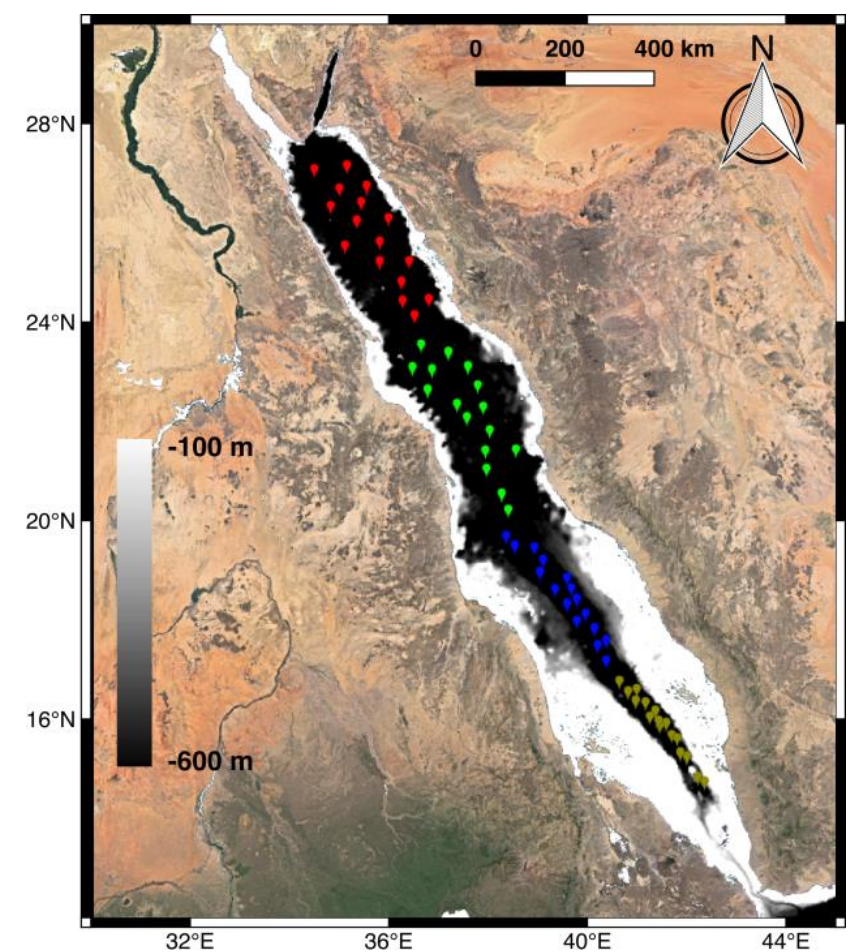

Fig. 1. The samples collected in the Red Sea, represented by colors (red: NRS, green: NCRS, blue: SCRS, olive: SRS), where the water depth $>100$ meters.

\section{B. NPP Models}

As noted previously, there are three different types of NPP models that will be discussed here: i) chlorophyll-based, ii) carbon-based and iii) phytoplankton absorption-based.

\section{1) Chlorophyll-based Model}

The generalized chlorophyll-based NPP model can be written as:

$N P P=\varphi \cdot \operatorname{chla} \cdot E$

$\varphi=\phi \cdot a_{p h}^{*}$

with NPP and $\varphi$ denoting PP and chlorophyll-normalized photosynthesis rate, which is in turn represented in equation (2) by the product of chlorophyll-specific absorption coefficients $\left(a_{p h}^{*}\right)$ and the efficiency factor for the energy conversion of each absorbed photon to the production of organic carbon $(\phi)$; chla is the chlorophyll concentration and $E$ is the absorbed photon energy. Since light changes spectrally with depth after penetrating the sea surface, it is notable that these two factors, depth and wavelength, must be accounted for while estimating $E$. Therefore, a common wavelength resolved (WR) model addressing this issue is implemented in equation (1) and is represented here as:

$$
\begin{aligned}
& N P P(z)=\int \varphi(z) \cdot \operatorname{chla}(z) \cdot E(\lambda, z) d \lambda \\
& E(\lambda, z)=E(\lambda, 0) e^{-K(\lambda) \cdot z}
\end{aligned}
$$

with $N P P(z), \varphi(z)$, chla $(z)$ and $E(\lambda, z)$ representing the PP, chlorophyll-normalized photosynthesis rate, chlorophyll concentration as a function of depth and absorbed photon energy at water depth $z$ and wavelength $\lambda . E(\lambda, 0)$ represents the surface spectral light energy with its spectral diffuse attenuation coefficient $K(\lambda)$, which is also calculated from $c h l$ for Case-1 waters. The photosynthesis of the whole water column (aka NPP) can then be derived from the integration of $N P P(z)$ over depth.

The VGPM [45] is a chlorophyll-based model whose photosynthesis rate is expressed as a function of water depth and photosynthetically active radiation (PAR). The VGPM estimates water column integrated productivity NPP as:

$N P P=$ chla $\cdot P_{o p t}^{B} \cdot h_{P A R} \cdot f(E)$
$f(E)=\frac{c_{1} \cdot \mathrm{PAR}}{\mathrm{PAR}+c_{2}} \cdot z_{e u}=\frac{0.66125 \cdot \mathrm{PAR}}{\mathrm{PAR}+4.1} \cdot z_{e u}$

with the chlorophyll concentration (chla), the maximum daily net PP within a given water column $\left(P_{o p t}^{B}\right)$ (in mg carbon fixed per mg chlorophyll per hour), daily hours of light $\left(h_{P A R}\right)$ and a volume function $f(E)$ that relies on the empirical parameters $\left(c_{1}=0.66125, c_{2}=4.1\right)$ to express the vertical decrease in PAR and the euphotic depth $\left(z_{e u}\right)$ (practically defined as the depth where the solar radiation is $1 \%$ of its surface value).

The $P_{o p t}^{B}$ is also derived by an empirically parametrized sea surface temperature (SST)-dependent polynomial equation:

$$
\begin{aligned}
& P_{o p t}^{B}=-3.27 \cdot 10^{-8} S S T^{7}+3.4132 \cdot 10^{-6} S S T^{6}-1.348 \\
& 10^{-4} S S T^{5}+2.462 \cdot 10^{-3} S S T^{4}-0.0205 S S T^{3}+ \\
& 0.0617 S S T^{2}+0.2749 S S T+1.2956
\end{aligned}
$$

The Eppley-VGPM is a modified version of the VGPM, which only replaces the 7 th degree polynomial expression of $P_{o p t}^{B}$ with the exponential function presented in [16], [46] given as:

$P_{o p t}^{B}=1.54 \cdot 10^{0.0275 \cdot \mathrm{SST}-0.07}$

\section{2) Carbon-based Model}

Historically, the chlorophyll-based model has been used as the only method to estimate the algal biomass. However, the Chla retrieval does not include the physiological adjustments of phytoplankton to the changing environments. The ratio between Chla and phytoplankton biomass is not stable but changing seasonally, through the variability of intracellular chlorophyll concentration in response to the environmental factors such as light acclimation and nutrient stress (aka. photoacclimation). The estimation of phytoplankton biomass recently became possible because phytoplankton carbon biomass could be estimated from the total particulate backscattering coefficient, owing to their covariance with light scattering properties [47][53], as well as stable relationship between phytoplankton carbon biomass $(C)$ and total particulate organic carbon. Moreover, the phytoplankton growth rates are now estimated from Chla to carbon ratios because the particle backscattering coefficient $\left(b_{b p}\right)$, the absorption of phytoplankton pigments, and the absorption of colored dissolved organic carbon can be 
obtained by applying spectral matching algorithms simultaneously to satellite data [54]-[56]. After applying the algorithms, the CbPM model is developed [13], [22] in which the NPP is presented as:

$N P P=C \cdot \mu \cdot f(E)$

with phytoplankton carbon $(C)$ derived empirically from its relationship to the measured $b_{b p}$ :

$C=13000 \cdot\left(b_{b p}-0.00035\right)$

where the value 13000 (in $\mathrm{mgC} / \mathrm{m}_{2}$ ) is the scaling factor introduced for the satellite chla:C ratios in consistent with the laboratory experiments, and the globally constant value 0.00035 (in m-1) is the particle backscattering coefficient of non-algal particles ( $b_{b p} \mathrm{NAP}$ ) [13]. In practice, when $b_{b p}<$ 0.00035 , the $C$ is set to 0.13 . The phytoplankton growth rate $(\mu)$ is calculated based on the chla: $C$ ratios:

$\mu=\mu_{\max } \cdot f(N, T) \cdot g\left(I_{g}\right)$

$g\left(I_{g}\right)=1-e^{-5 \cdot P A R_{M L}}$

where $\mu_{\text {max }}$ is the maximum growth rate; $f(N, T)$ refers to the nutrient and temperature stress and $g\left(I_{g}\right)$ describes reductions in growth rate with decreasing light at the mixed layer light level $\left(P A R_{M L}\right)$. Furthermore, the $f(N, T)$ is expressed empirically as parametrized $c h l: C$ ratios for the satellite observation (Chla: $C_{\text {sat }}$ ) and nutrient replete conditions (Chla: $C_{N, T_{\max }}$ ), which can also be derived from $P A R_{M L}[8]$ as shown in (13) and later modified by introducing $\varepsilon=0.0003$ as the chla: $C$ ratio when growth rate $\mu=0$ [22] as given in equation (14):

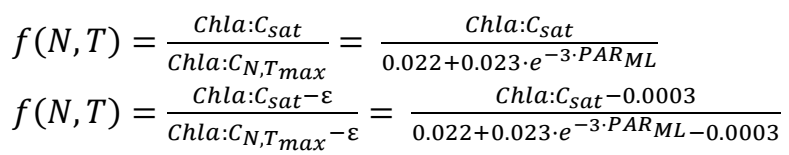

Finally $f(E)$, the volume function, describes the light change through the water column as:

$f(E)=I_{0} \cdot e^{\frac{-k_{490} \cdot \mathrm{MLD}}{2}}$

where $I_{0}$ is the cloud-corrected PAR just below the water surface, $k_{490}$ is the light attenuation coefficient at $490 \mathrm{~nm}$ and MLD is the mixed layer depth.

\section{3) Phytoplankton absorption-based Model}

Estimation of chlorophyll concentration in this model is based on the remote sensing reflectance $\left(R_{r s}\right)$ just above the surface. $R_{r s}$ can be directly derived based on the ratio between water leaving radiance $\left(\mathrm{L}_{w}\right)$ and downwelling irradiance just above the surface $\left(\mathrm{E}_{\mathrm{d}+}\right)$. Moreover, the $R_{r s}$ is usually obtained from the total absorption coefficient $(a)$ and the backscattering coefficient $\left(b_{b}\right)$. Two main things to be considered to accurately derive spatially and temporally varying Chla from $R_{r s}: 1$ ) Remove the influence of detritus/CDOM and particles and 2) Take into account the spatial/temporal variation of $a_{p h}^{*}$. However, the change of $b_{b}$ is relatively weaker than $a$ in the water [10], therefore the $R_{r s}$ is largely dependent on $a$, hence, allowing chlorophyll concentration to be retrieved from $a_{p h}$. Since from (2) $a_{p h}^{*}$ is the ratio of the phytoplankton absorption coefficient $\left(a_{p h}\right)$ and chla, combining equations (2) and (3) results in a modified and more generalized model presented as:

$N P P(z)=\int \phi(z) \cdot a_{p h}(\lambda, z) \cdot E(\lambda, z) d \lambda$

The new model expressed by (16) eliminates the need for $a_{p h}^{*}$ estimation, used previously in (3), hence avoiding a major source of uncertainty in the NPP calculation. On the other hand, the new model makes significant use of the $a_{p h}$ value that is directly derived from $R_{r s}$, a methodology that has been well developed and evaluated [57]-[65].

Here we selected three, chlorophyll and carbon based, models and performed inter-comparisons to investigate the seasonal to decadal trends of the NPP in the Red Sea region. The used models are VGPM, Eppley, and CbPM that share the same temporal resolution of 8-day \& monthly (averaged from daily products) and spatial resolutions of $1 / 12^{\circ}(9 \mathrm{~km})$. To account for the longest possible temporal variability over the Red Sea domain, data derived from SeaWiFS, MODIS and VIIRS sensors, spanning the periods 1998-2002, 2003-2018, and 2012-2018, respectively, were used. All three NPP model estimates are available via the website provided by Oregon State University (OSU: http://www.science.oregonstate.edu/ocean.productivity/). The phytoplankton absorptionbased model is not used here as, to the best of our knowledge, there are no standard NPP products of $a_{p h}$ from satellite oceancolor sensors yet.

\section{DATA AND METHODS}

\section{A. Model and Satellite Data}

Different NPP related parameters are obtained from the European Space Agency's GlobColour merged products using SeaWiFS, MERIS, MODIS Aqua, VIIRS and OLCI-A sensors (http://hermes.acri.fr/index.php?class=archive) to explore relationships using multilinear regression analysis.

These merged products are generated by different averaging techniques namely AV: simple averaging, AVW: weighted averaging, AN: analytical from other L3 products or by the Garver-Siegel-Maritorena (GSM) model method that uses the normalized reflectances at the original sensor wavelengths, without inter-calibration [66]. The performance of these weighting methods depends mainly on the surrounding environmental conditions representing water types, geographical region and glint/aerosol conditions. Hence, different parameters are investigated here for possible NPP 
interplay including: 1) Angström exponents at $550 \mathrm{~nm}$ (over land \& water) (A550) from MODIS [67] and MERIS [68] datasets; 2) particulate inorganic carbon (PIC) (mol/m3) generated from the original National Aeronautics and Space Administration (NASA) algorithms (2-band look-up table and 3-band algorithm at high concentrations) [69], [70]; 3) particulate organic carbon $(\mathrm{POC})\left(\mathrm{mol} / \mathrm{m}_{3}\right)$ generated from the original NASA algorithm (correlation of band ratios) [71]; 4) aerosol optical thicknesses at $550 \mathrm{~nm}$ (T550) (over land \& water) calculated from A550 [72]; 5) PAR (einstein/m2/day) [73] indicating the photon flux density from 400 to $700 \mathrm{~nm}$ for photosynthesis; 6) particulate backscattering coefficient $\left(b_{b p}\right)$ $(\mathrm{m}-1)$ at $443 \mathrm{~nm}$ generated from the GSM merging algorithm [66]; 7) the diffuse attenuation coefficient (m-1) (KD490) of the downwelling irradiance at $490 \mathrm{~nm}$ as an indicator of the turbidity of the water column, which is computed from corresponding merged chlorophyll products [74]; 8) MLD (m) provided by Global HYbrid Coordinate Ocean Model (HYCOM) [75] and downloaded from OSU website.

In order to assess the possible role and impact of dust on the NPP over the Red Sea, the monthly Modern-Era Retrospective Analysis for Research and Applications Version 2 (MERRA-2) atmospheric reanalysis data, including Dust Extinction AOT at $550 \mathrm{~nm}$, Wind speed, and Angström Exponent are used. SST and Chla $\left(\mathrm{mg} / \mathrm{m}_{3}\right)$ were obtained from NASA's Ocean Color Web site (https://oceancolor.gsfc.nasa.gov/). The MERRA-2 data extend from January 1980 to present and are produced by NASA based on historical analysis using the Goddard Earth Observing System Model, Version 5 (GEOS-5) with its Atmospheric Data Assimilation System (ADAS), version 5.12.4 [76], [77].

The phytoplankton absorption coefficient $a_{p h}(\lambda)$ averaged at wavelengths $\lambda_{s}$, which determines the amount of radiant energy captured by the phytoplankton community has been suggested to be more related to PP than Chla [78]-[80]. In this study, we spectrally averaged the $a_{p h}(\mathrm{APH})$, over the available wavelengths ranging from $412 \mathrm{~nm}$ to $670 \mathrm{~nm}$, derived from the Ocean Color CCI (OC-CCI) dataset (https://www.oceancolour .org/) [81] using the Quasi-Analytical Algorithm (QAA) [61], and then compared the results with the NPP derived from the three previously mentioned models. Table I lists all the datasets used in this work.

TABLE I

SUMMARY OF DATA IN THE STUDY

\begin{tabular}{|c|c|c|c|}
\hline Name & $\begin{array}{l}\text { Temporal } \\
\text { Resolution }\end{array}$ & $\begin{array}{c}\text { Spatial } \\
\text { Resolution }\end{array}$ & $\begin{array}{l}\text { Data } \\
\text { Source }\end{array}$ \\
\hline $\begin{array}{l}\text { VGPM } \\
\text { Eppley } \\
\text { CbPM }\end{array}$ & $\begin{array}{c}\text { 8-day } \\
\text { Monthly }\end{array}$ & $9 \mathrm{~km}$ & OSU \\
\hline $\begin{array}{c}\text { A550 } \\
\text { PIC } \\
\text { POC } \\
\text { T550 } \\
\text { PAR } \\
b_{b p} \\
\text { KD490 }\end{array}$ & 8-day & $4 \mathrm{~km}$ & GlobColour \\
\hline MLD & 8-day & $9 \mathrm{~km}$ & OSU \\
\hline APH412 & 8-day & $4 \mathrm{~km}$ & OC-CCI \\
\hline $\begin{array}{l}\text { Dust AOD } \\
\text { AE } \\
\text { Windspeed } \\
\end{array}$ & Monthly & $0.5^{\circ} \times 0.625^{\circ}$ & MERRA-2 \\
\hline $\begin{array}{l}\text { SST } \\
\text { Chla }\end{array}$ & $\begin{array}{c}\text { 8-day } \\
\text { Monthly }\end{array}$ & $4 \mathrm{~km}$ & NASA \\
\hline
\end{tabular}

\section{B. Comparison with Climate Indices}

It has been noted that NPP can be influenced by varying climatic patterns [26], [82], [83] in different geographical areas other than the Red Sea. We analyzed different climate indices for their impact on the NPP products derived from the previously mentioned models. Table II summarizes and describes the used climate parameters including: the North Atlantic Oscillation (NAO), the North Pacific Gyre Oscillation (NPGO), the Multivariate ENSO Index (MEI), the Pacific Decadal Oscillation (PDO) and the Dipole Mode Index (DMI).

To determine the possible impact of these climate indices and their relationship with NPP, we applied correlation analysis to the 12-month moving average of NPP anomalies in the four regions of the Red Sea domain against the different indices, as well as the 12-month moving average, as shown in Table II.

The NPP monthly anomaly is denoted as $\left(a_{m}\right)$ [26]:

$a_{m}=N P P_{m}-N P P_{t}$

TABLE II

SUMMARY OF CLIMATE INDICES

\begin{tabular}{|c|c|c|c|}
\hline \multirow{3}{*}{$\begin{array}{l}\text { Abbreviation } \\
\text { NAO }\end{array}$} & \multirow{2}{*}{\multicolumn{2}{|c|}{ Definition }} & \multirow[b]{2}{*}{ Data Source } \\
\hline & & & \\
\hline & $\begin{array}{l}\text { North Atlantic } \\
\text { Oscillation }\end{array}$ & $\begin{array}{l}\text { The NAO measures a climate pattern of North Atlantic Ocean } \\
\text { fluctuations by the difference of atmospheric pressure at sea level } \\
\text { (SLP) between the Icelandic Low and the Azores High. }\end{array}$ & $\begin{array}{l}\text { http://www.cpc.ncep.noaa.gov/prod } \\
\text { ucts/precip/CWlink/pna/nao.shtml }\end{array}$ \\
\hline NPGO & $\begin{array}{l}\text { North Pacific Gyre } \\
\text { Oscillation }\end{array}$ & $\begin{array}{l}\text { NPGO is a climate pattern that presents as the } 2 \text { nd dominant mode of } \\
\text { Empirical Orthogonal Function of sea surface height variability }(2 \text { nd } \\
\text { EOF SSH) in the Northeast Pacific. }\end{array}$ & http://www.03d.org/npgo/ \\
\hline MEI & $\begin{array}{c}\text { Multivariate El } \\
\text { Niño/Southern } \\
\text { Oscillation (ENSO) }\end{array}$ & $\begin{array}{l}\text { The MEI is the bi-monthly time series of the leading combined EOF of } \\
\text { five different variables, namely, SLP, SST, surface wind of combined } \\
\text { zonal and meridional components, and outgoing longwave radiation } \\
\text { (OLR), over the tropical Pacific basin }\left(30^{\circ} \mathrm{S}-30^{\circ} \mathrm{N} \text { and } 100^{\circ} \mathrm{E}-70^{\circ} \mathrm{W}\right) \text {. }\end{array}$ & $\begin{array}{l}\text { http://www.cdc.noaa.gov/people/kl } \\
\text { aus.wolter/MEI }\end{array}$ \\
\hline PDO & $\begin{array}{l}\text { Pacific Decadal } \\
\text { Oscillation }\end{array}$ & $\begin{array}{l}\text { The PDO is the leading EOF of mean SST anomalies during November } \\
\text { through March for the Pacific Ocean to the north of } 20^{\circ} \mathrm{N} \text { latitude. }\end{array}$ & http://jisao.washington.edu/pdo \\
\hline DMI & Dipole Mode Index & $\begin{array}{l}\text { DMI represents the intensity of the Indian Ocean Dipole by anomalous } \\
\text { SST gradient between the western equatorial Indian Ocean }\left(50^{\circ} \mathrm{E}-70^{\circ} \mathrm{E}\right. \\
\left.\text { and } 10^{\circ} \mathrm{S}-10^{\circ} \mathrm{N}\right) \text { and the south eastern equatorial Indian Ocean }\left(90^{\circ} \mathrm{E}-\right. \\
\left.110^{\circ} \mathrm{E} \text { and } 10^{\circ} \mathrm{S}-0^{\circ} \mathrm{N}\right) \text {. }\end{array}$ & $\begin{array}{l}\text { https://stateoftheocean.osmc.noaa.g } \\
\text { ov/sur/ind/dmi.php }\end{array}$ \\
\hline
\end{tabular}




\section{HERE TO EDIT) <}

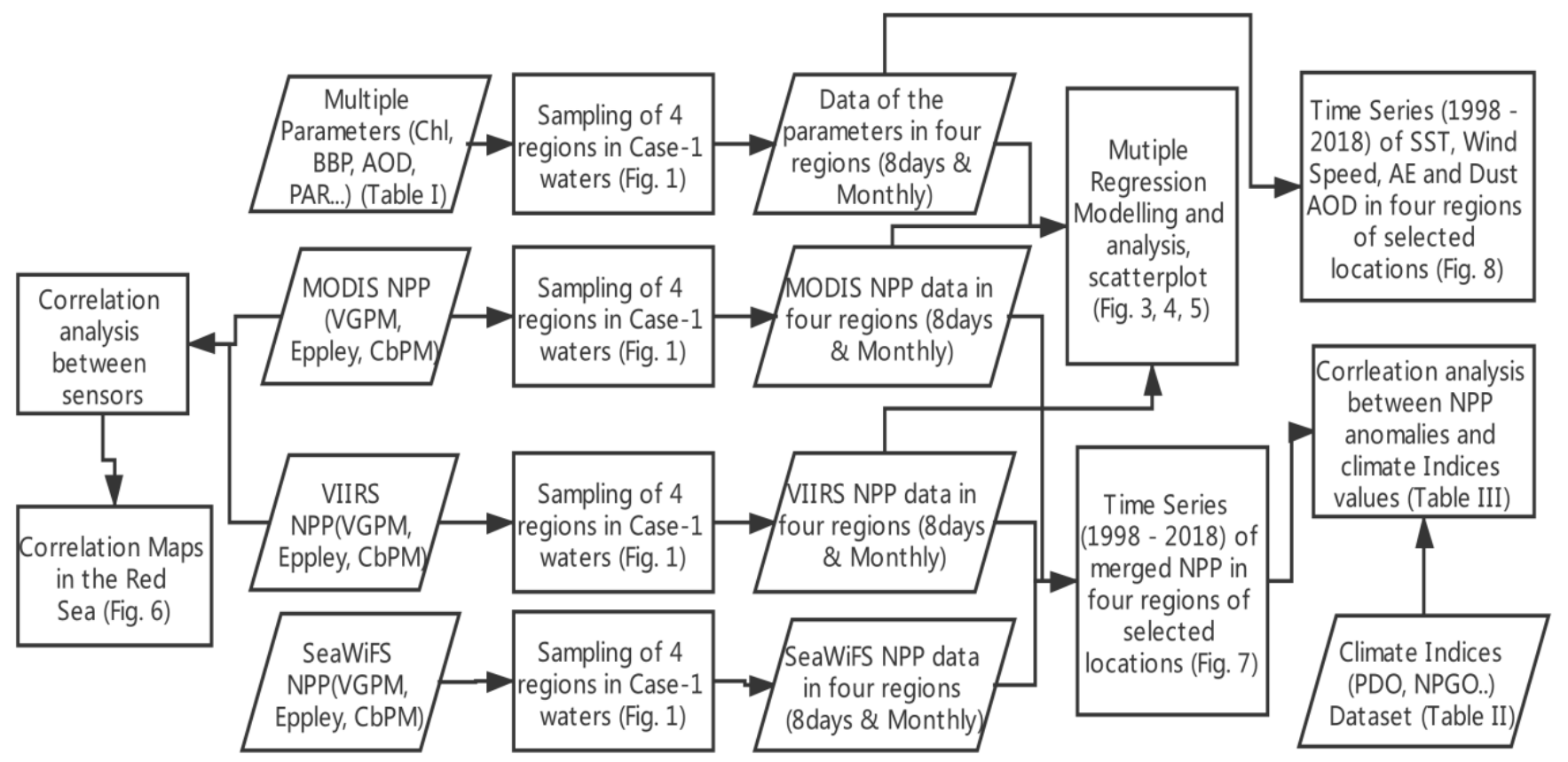

Fig. 2. The flowchart of this study.
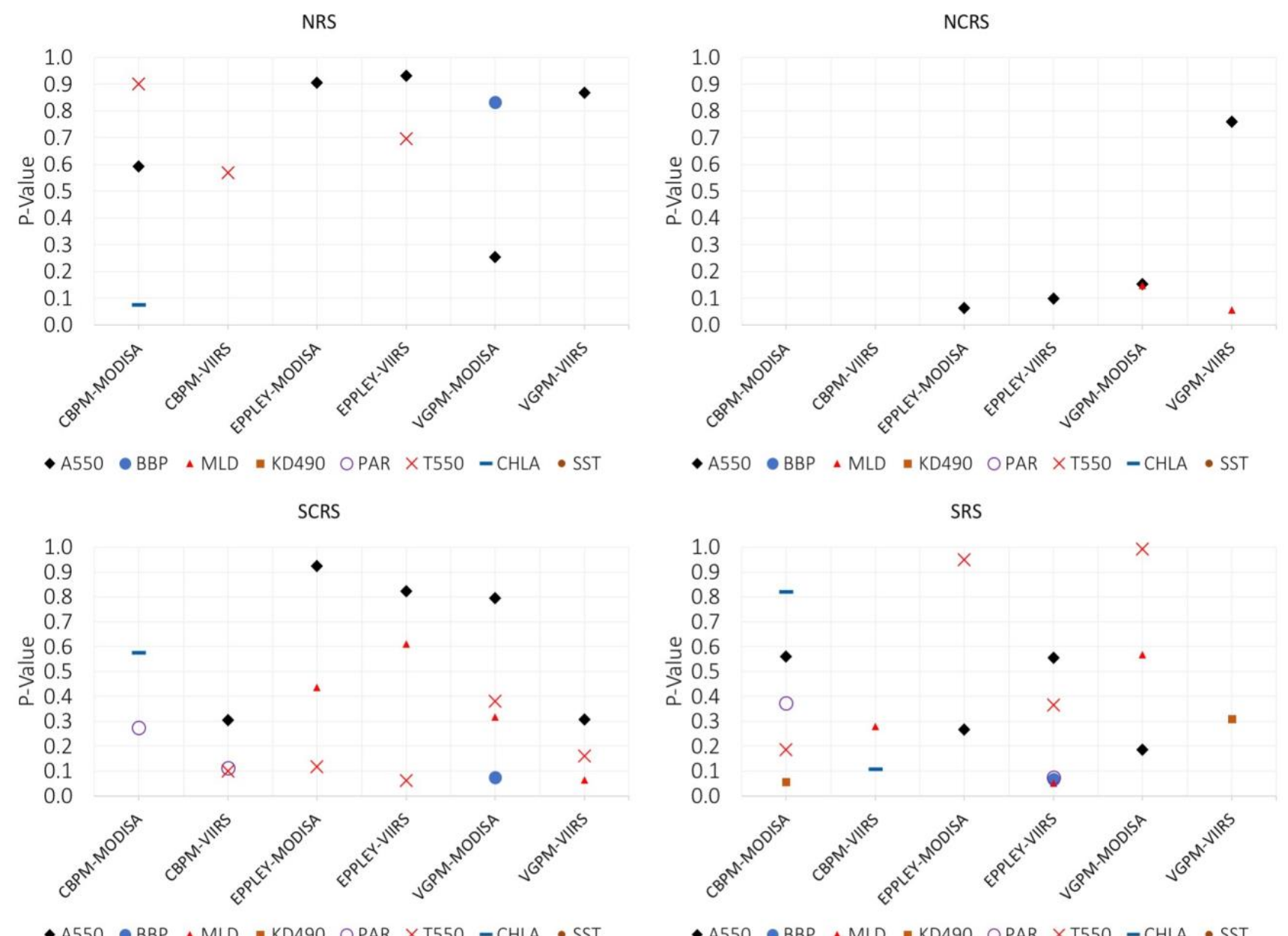

Fig. 3. The P-values of the variables (A550, MLD, T550, PAR, $b_{b p}$, KD490, SST and Chla) and the responding NPP model values, calculated from the multilinear regression model in each subregion (NRS, NCRS, SCRS and SRS) from both MODIS-Aqua (MODISA) and VIIRS sensors. 
with $N P P_{m}$ representing the NPP data during month $m$ and $N P P_{t}$ the monthly average over the entire time series. The 12month moving average for each $a_{m}$ was calculated by taking the average value from $a_{m}$ to $a_{m+11}$, then the monthly anomalies were scaled by the standard deviation of the values for that month $\left(\sigma_{m}\right)$ to obtain the $Z_{\text {score }}$ :

$Z_{\text {score }}=\frac{a_{m}}{\sigma_{m}}=\frac{N P P_{m}-N P P_{t}}{\sigma_{m}}$

\section{Correlative maps between Chla and NPP products}

For finding the relationship between Chla and NPP for each model, we developed correlation maps that show the standard correlation using the Pearson correlation coefficient $(r)$ in the range from -1 (anti-correlation) to +1 (perfect correlation), between these two monthly time series $x$ and $y$, with $N$ elements as:

$r=\frac{\sum_{i=1}^{N}\left(x_{i}-\bar{x}\right)\left(y_{i}-\bar{y}\right)}{\sqrt{\sum_{i=1}^{N}\left(x_{i}-\bar{x}\right)^{2}} \sqrt{\sum_{i=1}^{N}\left(y_{i}-\bar{y}\right)^{2}}}=\frac{\operatorname{Cov}(x, y)}{\sigma_{x} \sigma_{y}}$

with Cov being the covariance function, $\bar{x}$ and $\bar{y}$ the average and $\sigma_{x}$ and $\sigma_{y}$ the standard deviations for $x$ and $y$, respectively. The workflow of this study, with the table and figures presented in the following section is illustrated in the Fig. 2.

\section{RESUlts}

\section{A. Relationship between NPP and multiple parameters}

Statistical multilinear regression is applied to investigate the relationships between a set of variables (A550, MLD, T550, PAR, $b_{b p}$, KD490, SST and Chla) and the responding NPP model values in each region for both MODIS-Aqua (MODISA) and VIIRS sensors. These relationships are presented by Pvalues of each variable in the four subregions of Red Sea (Fig.3).

Figure 3 only shows the statistically insignificant variables P-values bigger than 0.05) for each dataset. The larger (insignificant) $\mathrm{P}$-value suggests that changes in the variables are not associated with changes in the NPP values. Both A550 and T550 are the mostly appeared variables while SST does not appear in any of the subregions. However, there are also some insignificant variables such as Chla and PAR (CbPM NPP), $b_{b p}$ and MLD (Eppley and VGPM NPP), as well as KD490 (CbPM, Eppley and VGPM NPP) particularly in the SCRS and SRS. Additionally, the Fig. 4 presents the adjusted coefficient of determination $\left(\mathrm{R}_{2}\right)$ for the multilinear regression model to show the proportion of the variance in the NPP dataset that is predictable from the variables. This figure shows that: 1) both VGPM and Eppley NPP products are notably related to the variables than that of CbPM, where the variables can explain most of the variance in the VGPM-VIIRS dataset $\left(\mathrm{R}_{2}>0.8\right)$ but fail to demonstrate that of CbPM-MODISA dataset $\left(\mathrm{R}_{2}<0.2\right)$; and 2) the NPP values in SCRS are generally less related to the variables compared to other regions of the Red Sea.

According the equations in section III and results from Figs. $3 \& 4$, the scatterplots to show the relationships between NPP products and selected variables ( $b_{b p}$, PAR, SST, MLD), including the spectral averaged $a_{p h}(\mathrm{APH})$, are illustrated in

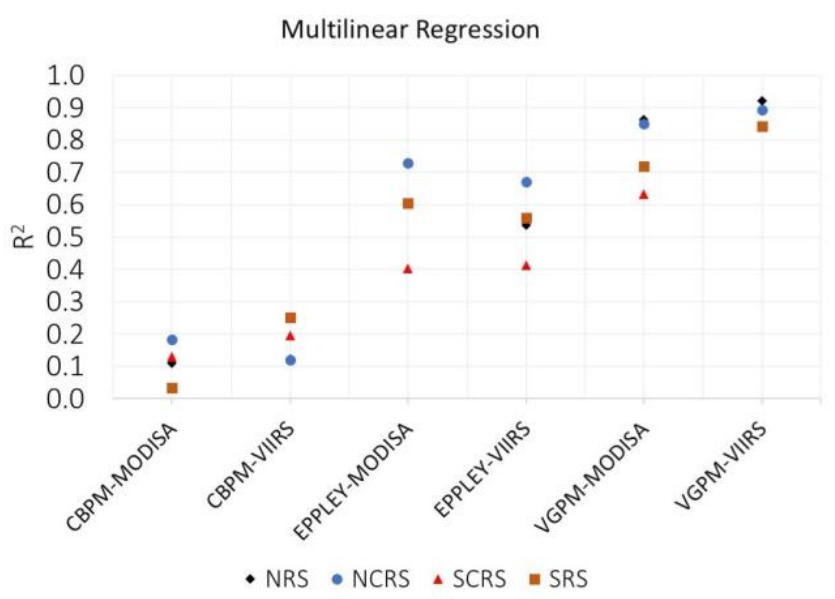

Fig. 4. The relationship between the combination of the values of variables (A550, MLD, T550, PAR, $b_{b p}$, KD490, SST and Chla) and the responding NPP model values, which is represented by the $R_{2}$ values of multilinear regression model in each subregion (NRS, NCRS, SCRS and SRS) from both MODIS-Aqua (MODISA) and VIIRS sensors.

Fig.5. The concentration of Chla is set by color levels. The increasing gradient in NPP from north to the south of Red Sea is generally consistent in all the three NPP models. However, the CbPM NPP has a lower median value in the SCRS than in the NCRS and NRS. Unreasonable low values $(<100)$ also appear in the CbPM NPP products. In Fig. 5a, a wider $b_{b p}$ value range (0-0.004 m-1) exists in SRS than the other regions (0-0.002) for both VGPM and Eppley products and the high values $\left(b_{b p}>0.003 \mathrm{~m}-1\right)$ correspond to greater Chla and NPP values, while such a relationship does not exist in CbPM products. In general, the NRS has greater PAR values than the southern Red Sea (Fig. 5b). In the SCRS and SRS, high VGPM and Eppley NPP values are usually observed at the PAR range 40-45 einstein/m2/day, as well as 55-60 einstein/m2/day but with many missing Chla values. Similar to $b_{b p}$, PAR has no linear relationship with CbPM products in all regions. In Fig. $5 c$, median values of SST are higher in the NRS than the SRS.

The VGPM product shows an apparent negative relationship with SST in the NRS, NCRS, and SCRS. The Eppley product shows a positive relationship in the SRS due to the settings of equation (7). Certain high NPP values are observed in the SCRS within SST ranging from 25 to 28 degrees, implying the impact of eddy activities. A positive relationship is found between MLD and VGPM NPP, particularly in regions with low Chla values (purple and blue dots in Fig. 5d). However, some high Chla and NPP values co-occur with the lowest MLD (<20 m) for both VGPM and Eppley products in the SCRS. The median value of MLD in the SRS is much lower $(\sim 25 \mathrm{~m})$ than the three other regions $(\sim 35 \mathrm{~m})$. There is an increasing gradient of APH median value along NRS $(<0.01 \mathrm{~m}-1)$ to SRS $(>0.03 \mathrm{~m}-1)$ (Fig. 5e). The positive relationship with APH and VGPM and Eppley NPP is also noted, especially in the SCRS and SRS, but not in the $\mathrm{CbPM}$ product.

\section{B. Comparison between NPP products between sensors}

The Red Sea was observed by both MODIS Aqua and VIIRS sensors during the year 2012 till 2018, which made it plausible 

HERE TO EDIT) <

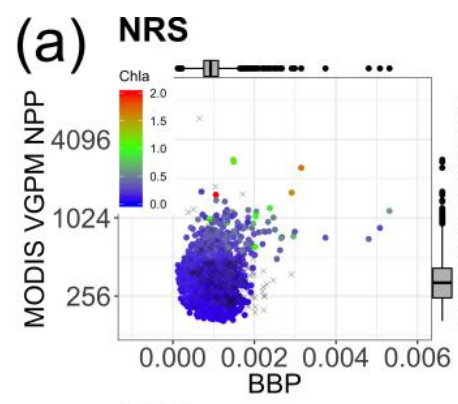

NRS

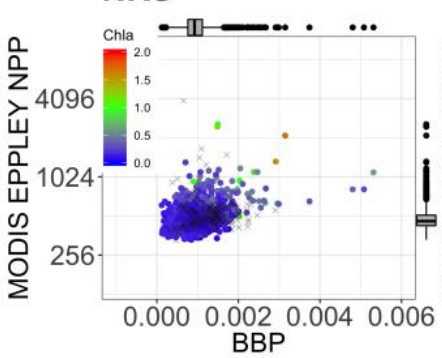

NRS

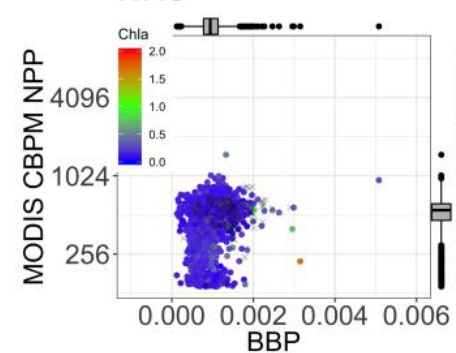

(b) NRS

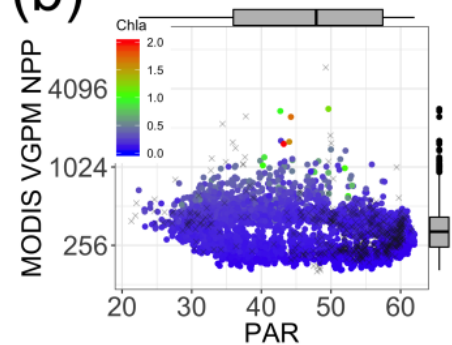

NRS

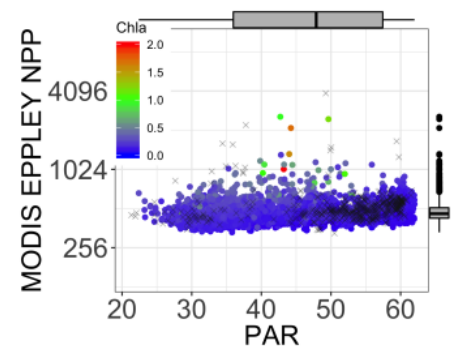

NRS

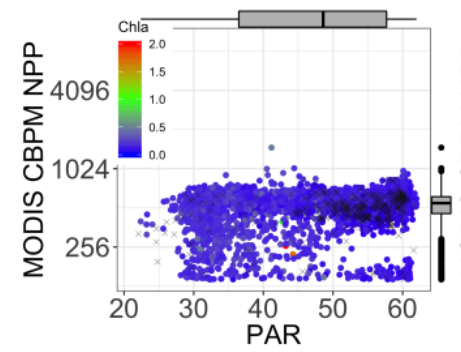

NCRS

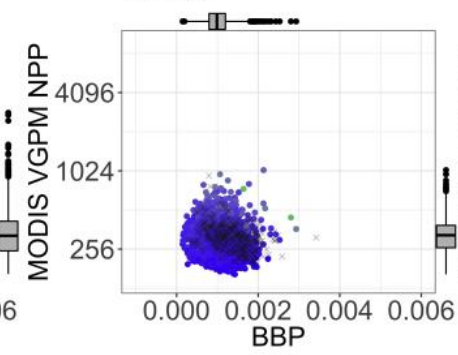

NCRS

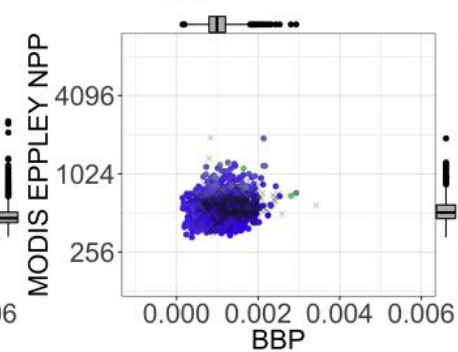

NCRS

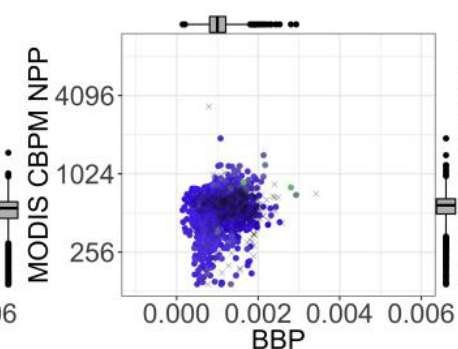

NCRS
SCRS

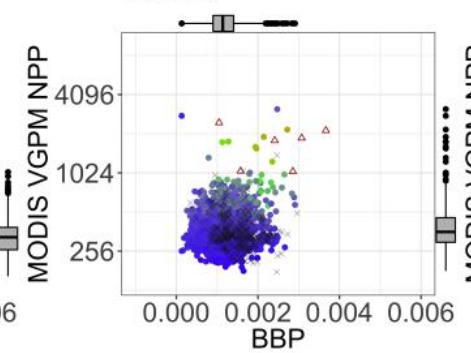

SCRS

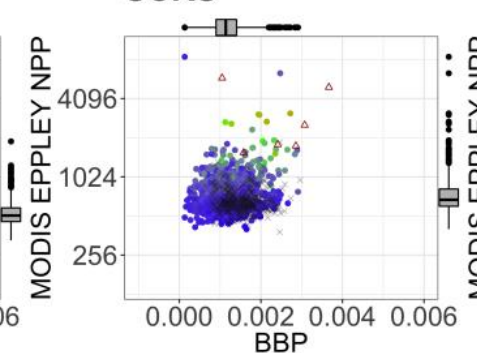

SCRS

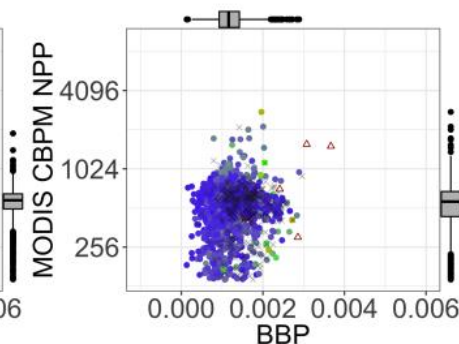

SCRS

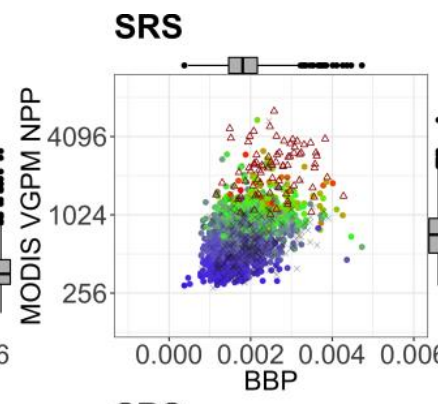

SRS

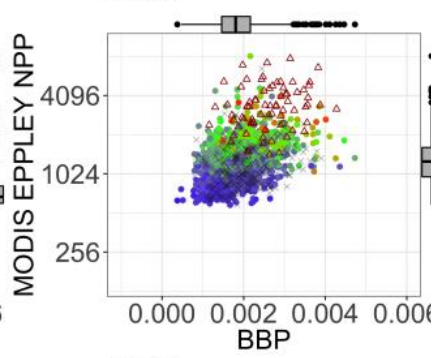

SRS

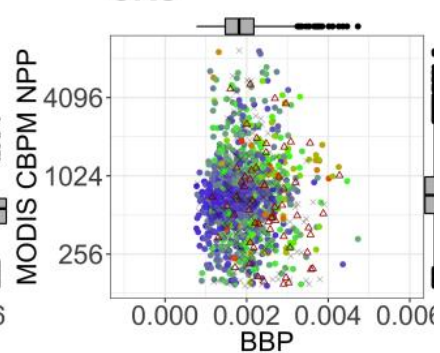

SRS
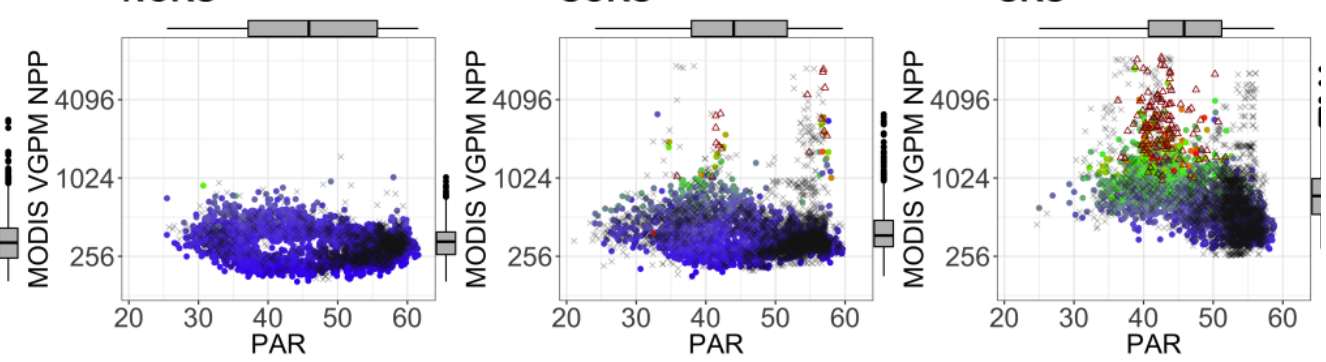

NCRS

SCRS

SRS
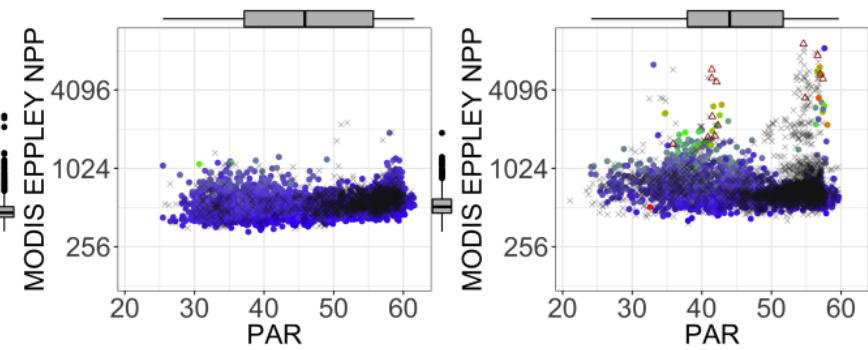

SCRS

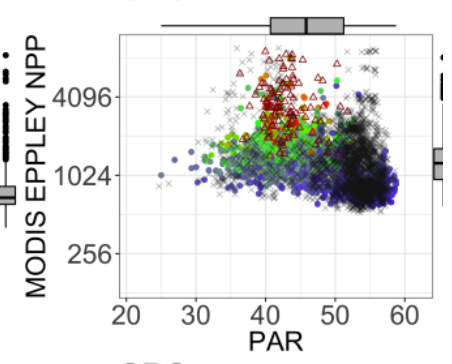

SRS

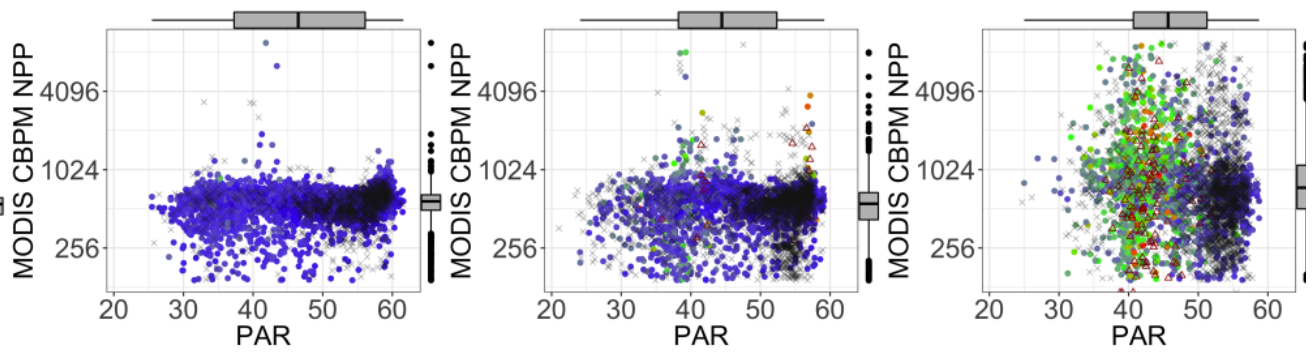



HERE TO EDIT) <

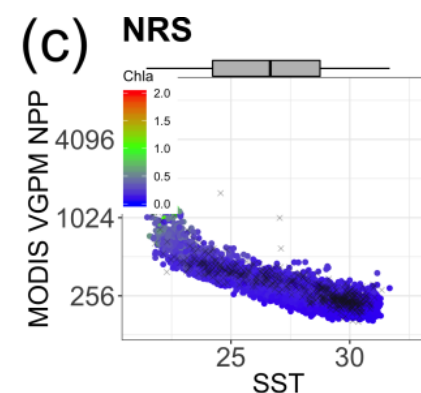

NRS

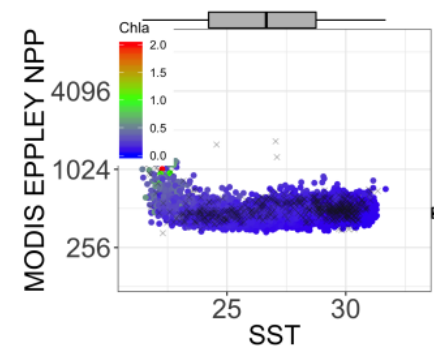

NRS

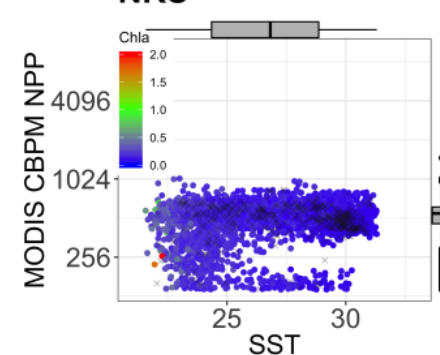

(d) NRS

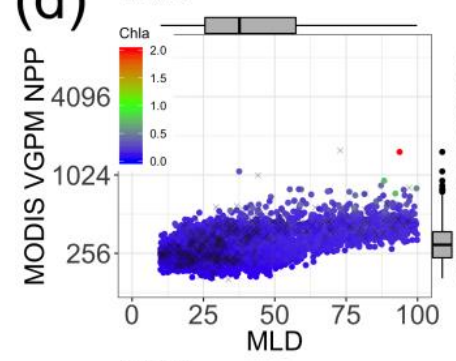

NRS

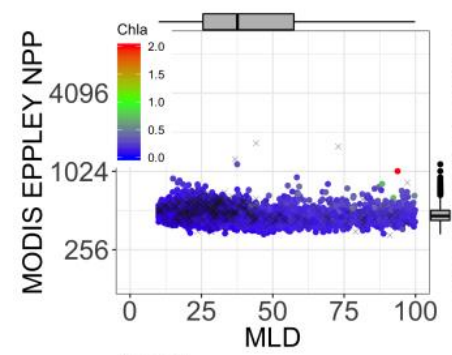

NRS
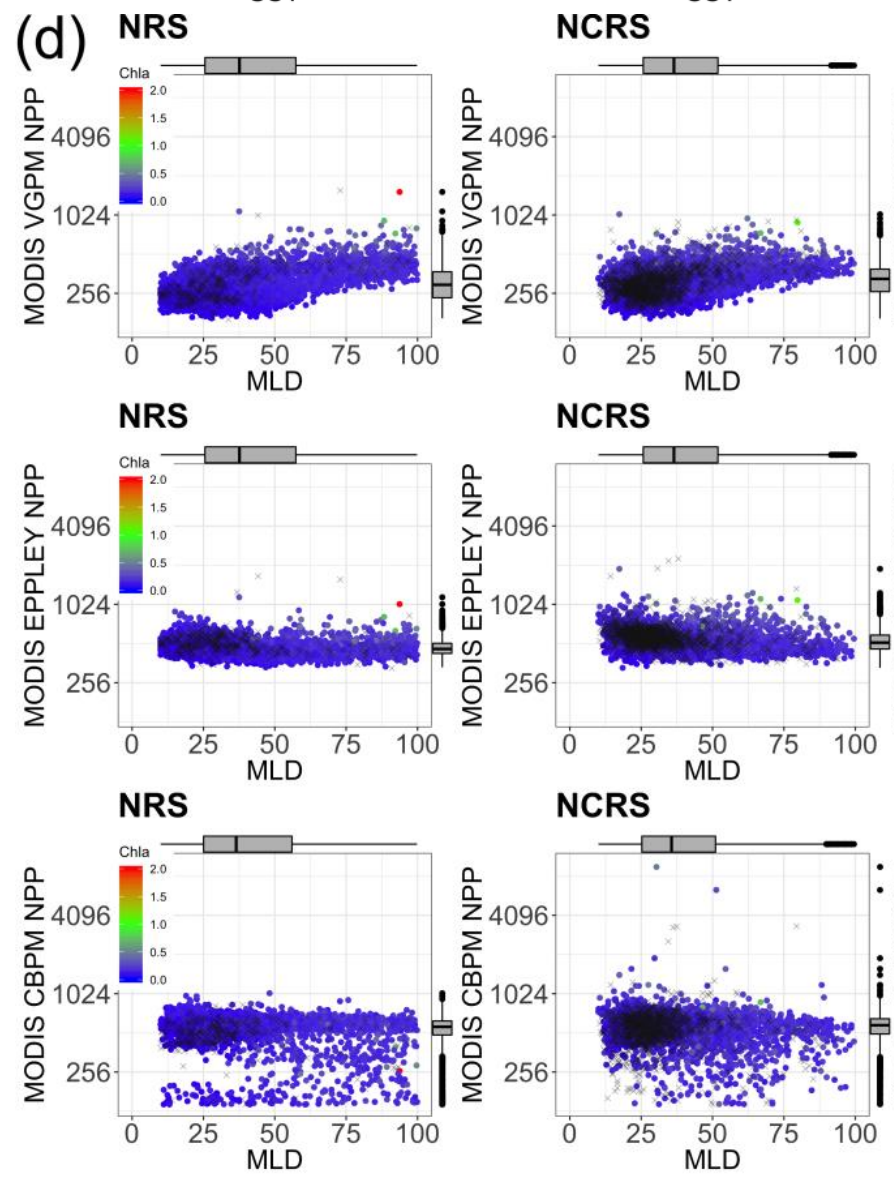

NCRS

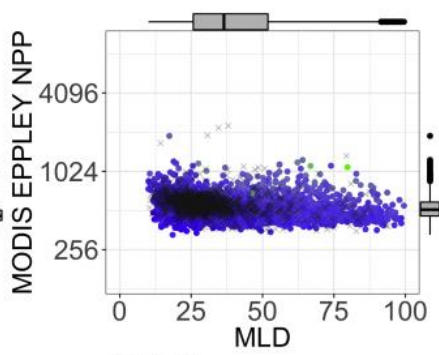

NCRS
SCRS

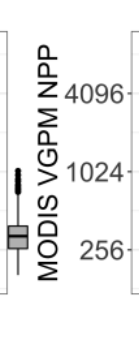

NCRS

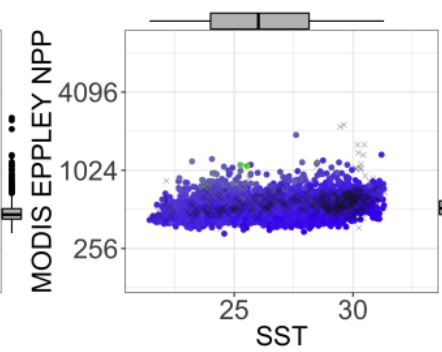

NCRS

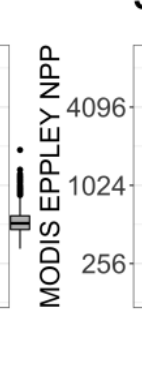

SCRS

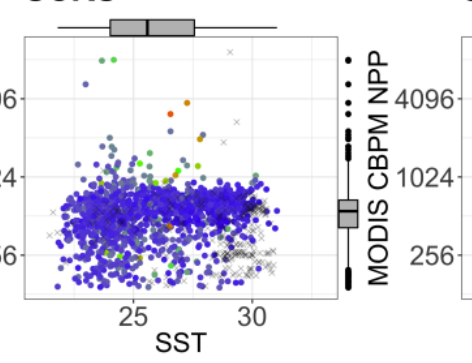

SRS
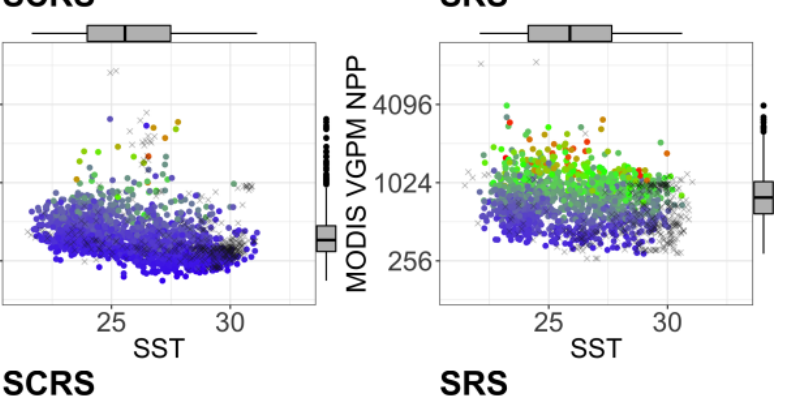

SRS

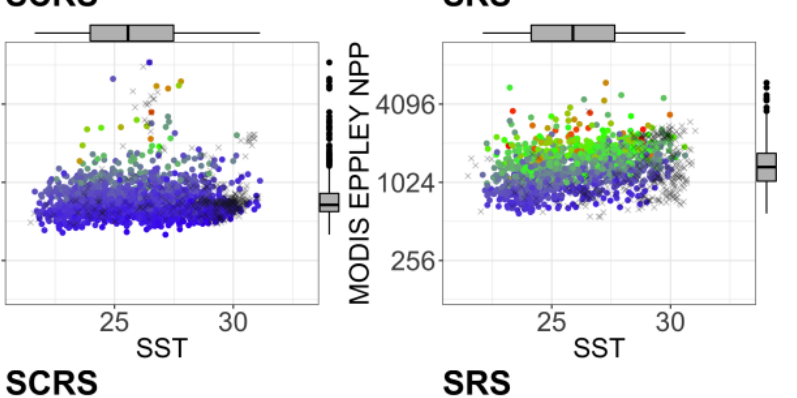

SRS

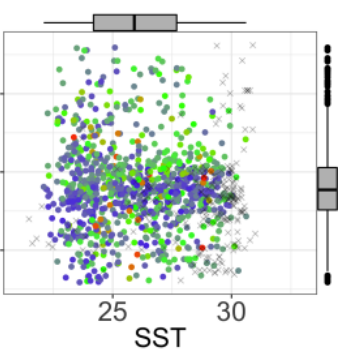

SRS
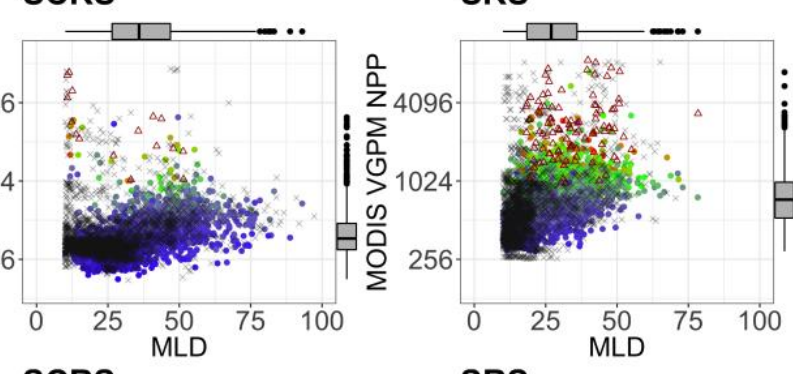

SCRS

SRS

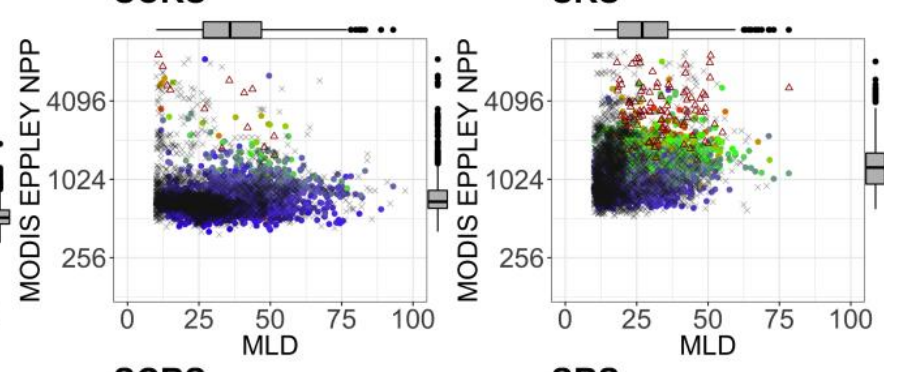

SCRS

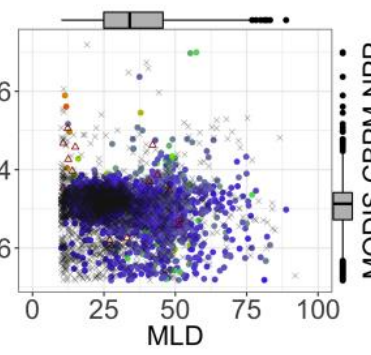

SRS

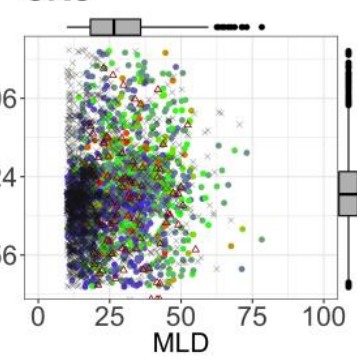



HERE TO EDIT) <
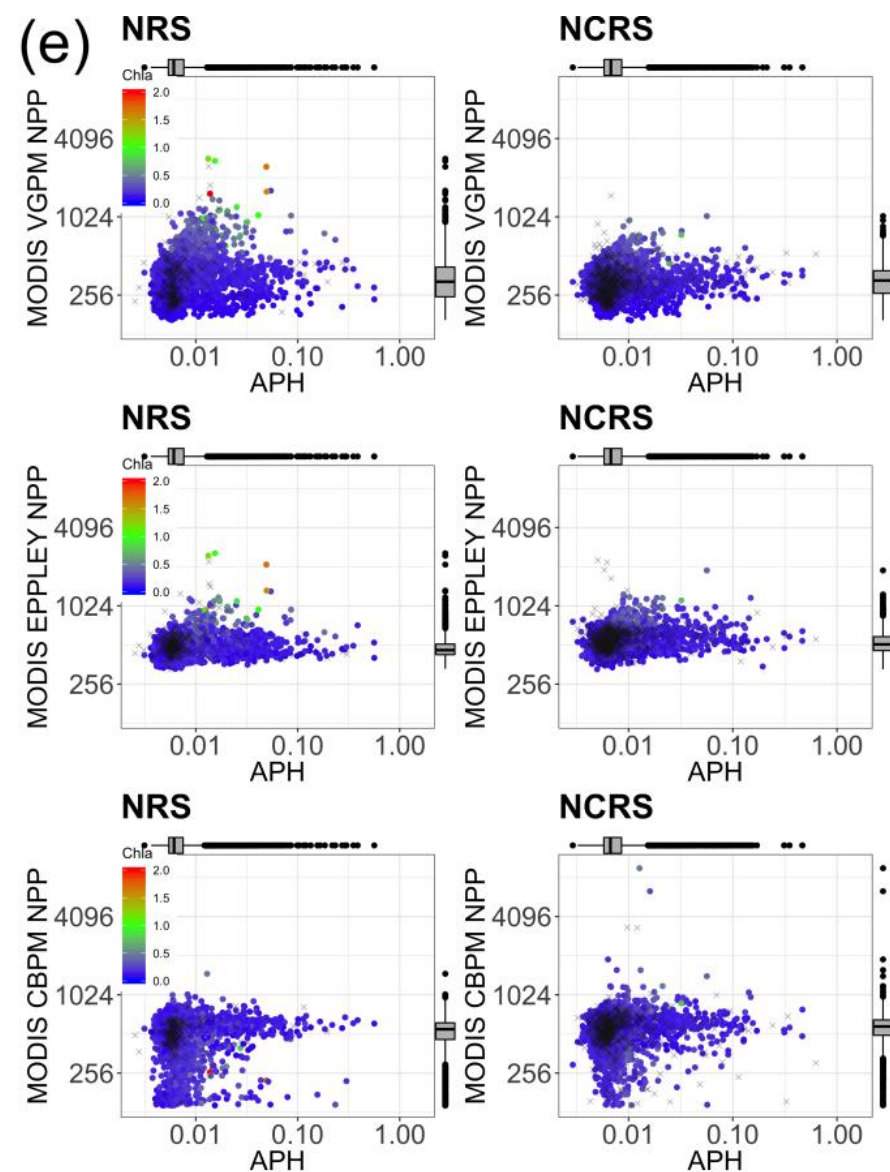

NCRS

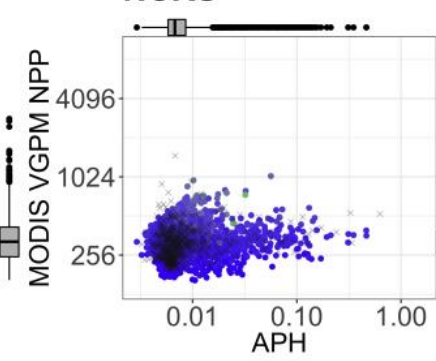

NCRS

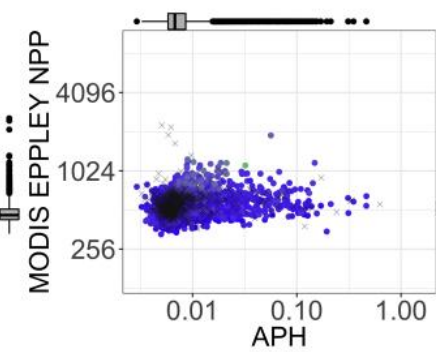

NCRS

$\mathrm{APH}$
SCRS

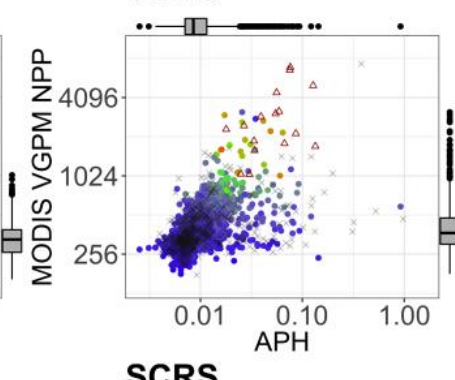

SCRS

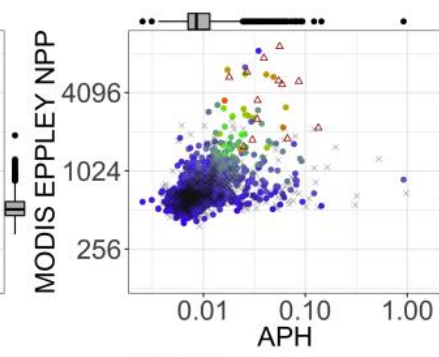

SCRS

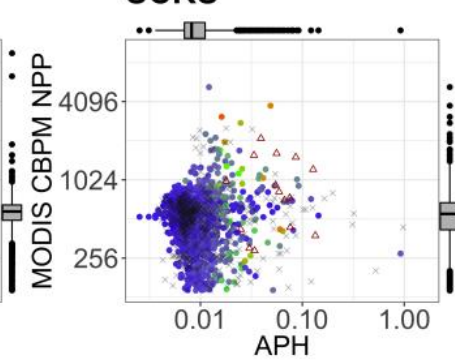

SRS

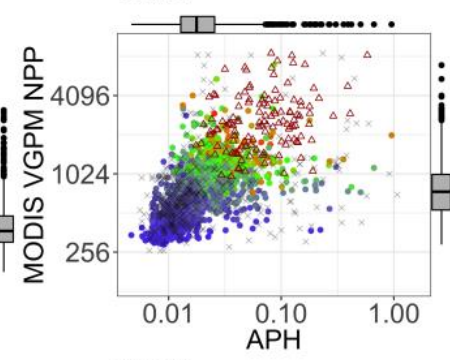

SRS

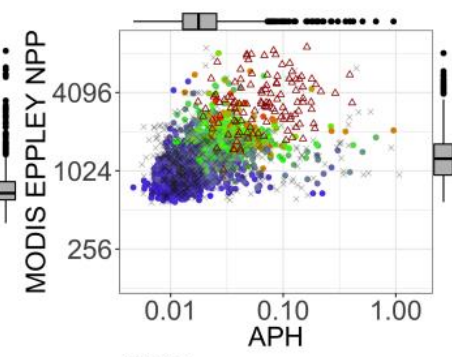

SRS

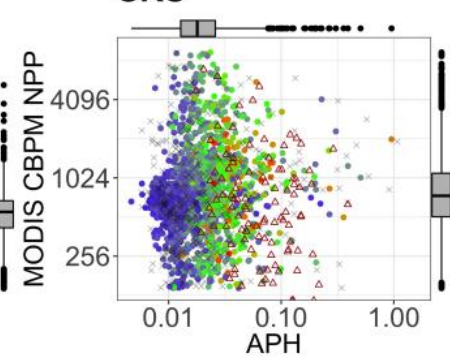

Fig. 5. The scatter plot (with colored Chla values) between NPP products (in log2 scale) and a) $b_{b p}$, b) PAR, c) SST, d) MLD and e) APH (in log10 scale). Grey points refer to missing Chla values and red delta values refer to Chla $>2 \mathrm{mg} / \mathrm{m} 3$. Boxplots are to show ranges and median value for NPP and variables.

products, including Chla and NPP models (CbPM, Eppley and VGPM) during the same period are presented in Fig. 6.

As shown in Fig. 6a, the Chla products from both MODIS and VIIRS sensors have strong correlation values $(r>0.6)$ for most regions of the Red Sea in the periods, with a decreasing gradient from north to south. The highest correlation $(r>0.8)$ observed in the SCRS are related to strong eddy activities [31], [41]. However, this relationship is not pronounced in the SRS
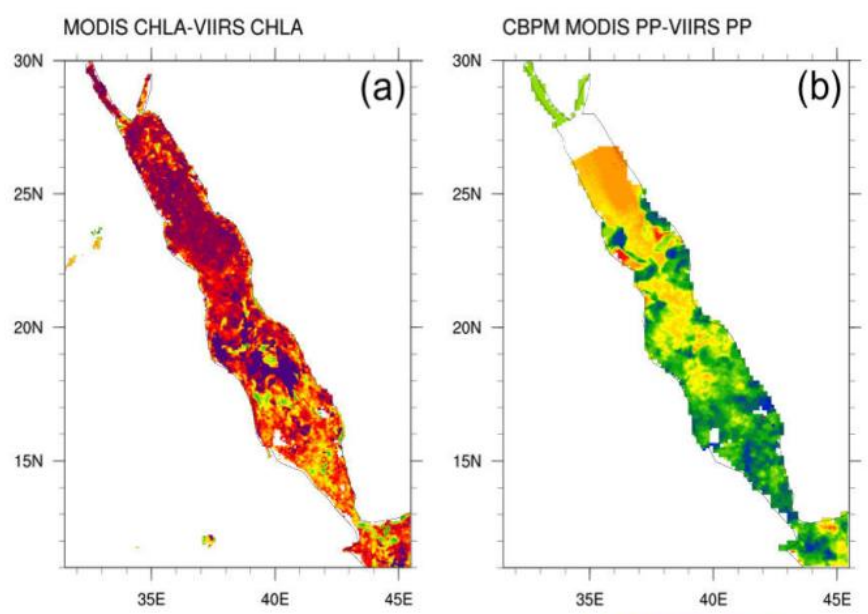

$(\mathrm{r}<0.6)$. The correlation map of CbPM NPP products in Fig. $6 \mathrm{~b}$ demonstrates a mismatch between MODIS and VIIRS sensors. Only moderate correlation $(\mathrm{r} \sim 0.5)$ was observed in the NRS, while other regions show low correlation $(r<0.3)$ or even negative correlation in the SRS. This result goes against the hypothesis that coherency should remain within CbPM products. On the contrary, Eppley products show great consistency between MODIS and VIIRS sensors $(r>0.9)$ in all
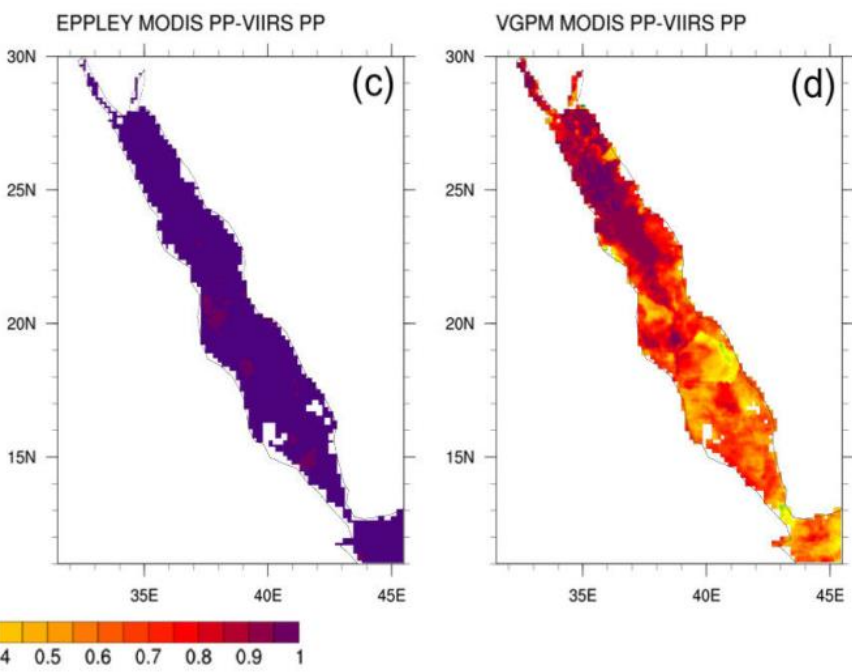

Fig. 6. Correlation map between MODIS and VIIRS products, including 8days Chla, CbPM NPP, Eppley NPP and VGPM NPP. 

HERE TO EDIT) <
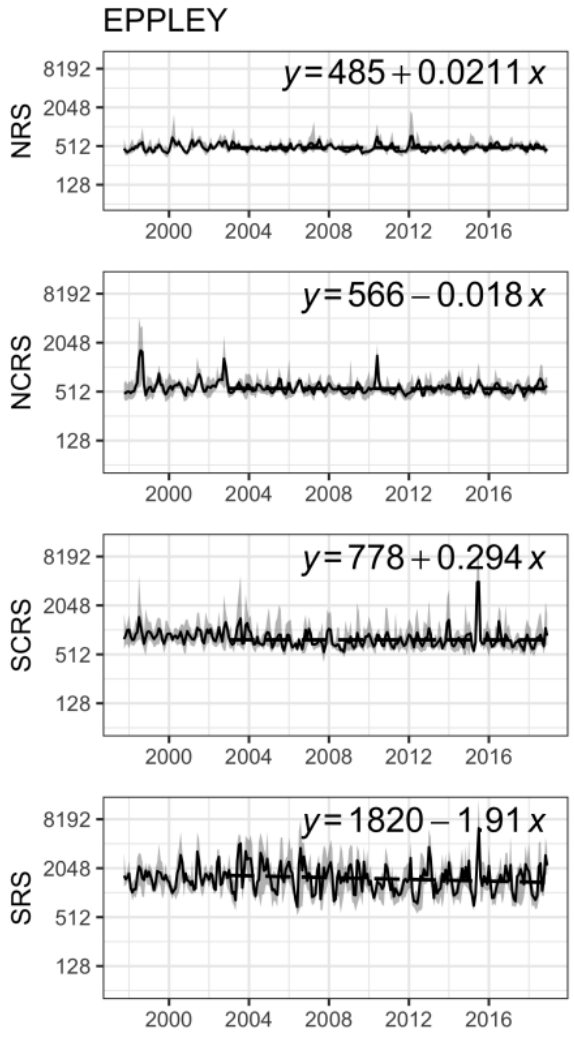
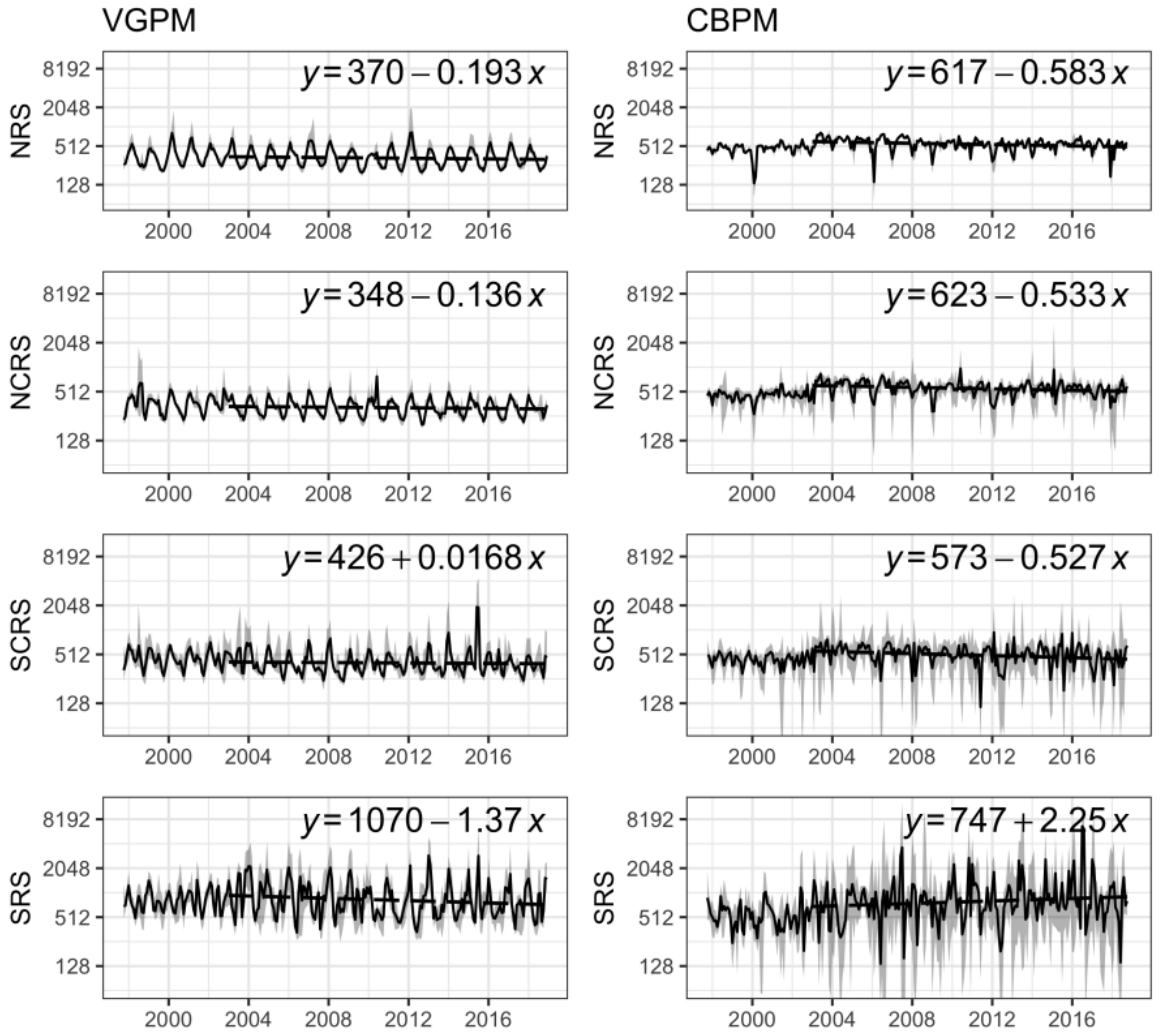

Fig. 7. Time series (values including SeaWiFS during the year 1997-2001 and MODIS: 2002-2018) to show trends for EPPLEY, VGPM and CbPM NPP for each region. The solid lines refer the mean value among the observations, whereas the shaded area shows the maximum and minimum value.

regions (Fig. 6c). The maps presented in the Fig. 6d exhibit a similar gradient pattern as shown in Fig. 6a, indicating the deciding role of Chla for VGPM products, yet the eddy-induced strong correlation in SCRS disappears.

The variations of each NPP product are shown in the time series for all the regions from 1997 to 2018 (Fig. 7). This figure suggests that the difference between SeaWiFS and MODIS remotely sensed data were not related to the NPP values. The NPP values before 2002 (SeaWiFS-based) are systematically lower than those after 2002 (MODIS-based), as presented in the CbPM time series. The intercepts of linear equations in the new Fig. 7 show the base levels of NPP for each region as a clear increasing gradient from north to south Red Sea. The southern Red Sea has more volatile NPP values than the north (significant gaps between maximum and minimum values). For VGPM and Eppley, the highest values commonly exist in the SRS (e.g., high values during May-1998 can be due to the strong ENSO event), with some exceptions such as high NPP events in the SCRS during the summer of 2015, which resulted from an eddy-driven phytoplankton event in the SCRS [70]. However, the CbPM derived NPP is more variable than VGPM and Eppley, with many extremely low values in the SCRS and SRS. In general, NPP values are estimated as highest in Eppley and lowest in VGPM, yet CbPM tends to overestimate NPP values in NRS and NCRS, even higher than those in SCRS. CbPM and other two NPP models indicate different trends: CbPM shows a rapid increase of NPP in SRS (2.25 mg C m-2 day-1 month-1) but VGPM and Eppley exhibit a decreasing trend
(1.37 and $1.91 \mathrm{mg} \mathrm{C} \mathrm{m-2} \mathrm{day-1} \mathrm{month-1,} \mathrm{respectively).}$

\section{Environmental Forcing for the NPP trend}

The variation of environmental forcing including SST, wind speed, Dust AOD and Angström Exponent (AE) are presented in the Fig. 8. This figure shows that SST has increased for all four regions since 2003 . For instance, the NRS has an annual increase of $0.0041{ }^{\circ} \mathrm{C}$ per month, meaning a $\sim 0.78{ }^{\circ} \mathrm{C}$ increase from 2003 to 2018. In addition, seasonal patterns of wind speed in the NRS, NCRS and SCRS are not as apparent as in the SRS, which has the highest wind speeds in boreal winter and lowest wind speeds in summer (May or June) but having a lower peak usually in July. The wind speed in SRS is negatively correlated $(\mathrm{r}=-0.47)$ with dust AOD and positively with AE $(r=0.16)$. Decreasing trends of windspeed are observed in the NRS and NCRS, whereas increasing trends are found in the SCRS and SRS. Moreover, AOD values show an increasing trend since 2014 for the NRS, SCRS, and SRS, especially during the summer seasons. This may be due to increase in the summer dust events and also the highest temperature ever recorded occurring from 2015 to 2018, which were the top four warmest years in the global temperature record [84], [85]. Unlike wind speed, the AE in all the regions shows strong seasonality, as well as an increasing trend. 

HERE TO EDIT) <

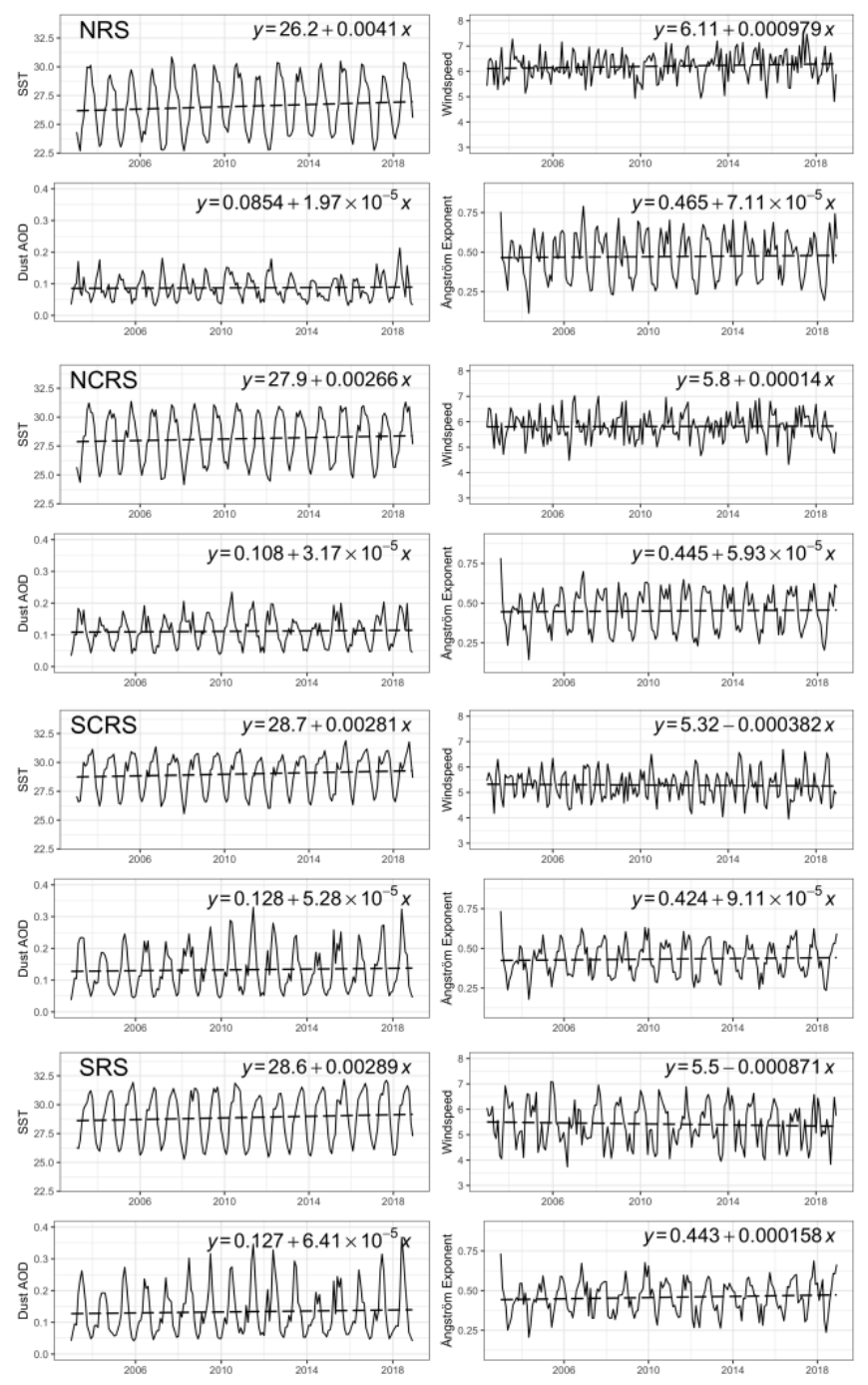

Fig.8. Trends of environmental forcing, including SST, AOD, windspeed and Angström exponent for the subregions of Red Sea.

\section{Teleconnections between NPP and climate indices}

Correlation analysis between NPP (on average, max, and min) anomalies values $\left(a_{m}\right)$ of CbPM, VGPM and Eppley models and the moving average values of multiple climate indices are shown in Table III. The highlighted values have been validated by the Pearson significance test (P-value $<0.05$ ). Here, positive correlation exists between MEI/PDO indices and CbPM values in the NRS, NCRS, and SCRS. However, such strong connections are not observed in the VGPM and Eppley models. All the NPP products are generally not responsive to the DMI and NAO indices, but seem more reactive to NPGO, while showing opposite relationships: CbPM is negatively correlated to NPGO, yet VGPM and Eppley are positively correlated to NPGO.

\section{DiscUSSION AND CONCLUSION}

Similar approaches to compare the performance of VGPM, Eppley and CbPM NPP models for regional applications have been reported in recent studies [83], [86]. An assessment of 36
NPP models, including VGPM, Eppley and CbPM, was undertaken to examine their ability to estimate the NPP trend, variability and mean value in the Bermuda Atlantic Time series Study (BATS) and the Hawaii Ocean Time series (HOT) datasets [26]. The study validated the argument that the model skill is not always improved by increased model complexity [23], [25]. Nevertheless, the mean NPP values at both sites were underestimated by most of the 36 models. For HOT, all three models have similar skills. However, at BATS, the CbPM model had the lowest skill among all the models, while VGPM and Eppley achieved much lower biases. It was also found in the Fig. 6 that CbPM model showed the strongest inconsistency between MODIS and VIIRS products. Since VGPM and Eppley only use PAR, SST and Chla as model inputs while CbPM uses additional optical parameters (i.e., $b_{b p}$ and KD490), such increased complexity of CbPM does not improve yet worsen its reliability. The poor performance of CbPM may also be explained by its close relationship to MLD, which was affected by season and latitude [87]. In addition, the NPP is significantly enhanced by the presence of mesoscale eddies [88]. Both the variability of MLD and eddy activities result in interannual changes of nutrients necessary for phytoplankton growth [89].

TABLE III

CORRELATION BETWEEN NPP (AVERAGE, MAX AND MIN) ANOMALIES VALUES AND THE MOVING AVERAGE VALUES OF MULTIPLE CLIMATE INDICES

\begin{tabular}{|c|c|c|c|c|c|c|}
\hline Average & & DMI & MEI & $\mathrm{NAO}$ & NPGO & PDO \\
\hline \multirow[t]{3}{*}{ NRS } & VGPM & 0.02 & -0.10 & 0.04 & 0.30 & -0.11 \\
\hline & Eppley & 0.07 & 0.13 & 0.03 & 0.12 & 0.19 \\
\hline & CbPM & 0.04 & 0.37 & -0.14 & -0.42 & 0.44 \\
\hline \multirow[t]{3}{*}{ NCRS } & VGPM & -0.20 & -0.04 & -0.08 & 0.42 & -0.13 \\
\hline & Eppley & -0.30 & 0.09 & -0.11 & 0.23 & 0.01 \\
\hline & CbPM & 0.03 & 0.40 & -0.22 & -0.45 & 0.46 \\
\hline \multirow[t]{3}{*}{ SCRS } & VGPM & -0.20 & 0.17 & 0.12 & 0.38 & 0.06 \\
\hline & Eppley & -0.26 & 0.20 & 0.12 & 0.35 & 0.12 \\
\hline & CbPM & -0.05 & 0.37 & -0.12 & -0.36 & 0.35 \\
\hline \multirow[t]{3}{*}{ SRS } & VGPM & -0.17 & 0.20 & -0.01 & -0.09 & 0.11 \\
\hline & Eppley & -0.20 & 0.23 & 0.05 & -0.08 & 0.16 \\
\hline & $\mathrm{CbPM}$ & 0.26 & 0.24 & -0.10 & -0.47 & 0.37 \\
\hline Max & & DMI & MEI & NAO & NPGO & PDO \\
\hline \multirow[t]{3}{*}{ NRS } & VGPM & 0.08 & -0.20 & -0.11 & 0.41 & -0.27 \\
\hline & Eppley & 0.06 & -0.02 & -0.14 & 0.28 & -0.04 \\
\hline & $\mathrm{CbPM}$ & 0.05 & 0.38 & -0.16 & -0.39 & 0.42 \\
\hline \multirow[t]{3}{*}{ NCRS } & VGPM & -0.29 & -0.03 & -0.24 & 0.41 & -0.17 \\
\hline & Eppley & -0.35 & 0.05 & -0.25 & 0.33 & -0.10 \\
\hline & CbPM & 0.07 & 0.34 & -0.24 & -0.46 & 0.41 \\
\hline \multirow[t]{3}{*}{ SCRS } & VGPM & -0.17 & 0.18 & 0.09 & 0.15 & 0.08 \\
\hline & Eppley & -0.21 & 0.18 & 0.12 & 0.16 & 0.09 \\
\hline & CbPM & 0.08 & 0.32 & -0.19 & -0.44 & 0.34 \\
\hline \multirow[t]{3}{*}{ SRS } & VGPM & -0.12 & 0.22 & -0.02 & -0.27 & 0.17 \\
\hline & Eppley & -0.11 & 0.26 & 0.03 & -0.29 & 0.21 \\
\hline & $\mathrm{CbPM}$ & 0.30 & 0.11 & -0.06 & -0.51 & 0.21 \\
\hline Min & & DMI & MEI & NAO & NPGO & PDO \\
\hline \multirow[t]{3}{*}{ NRS } & VGPM & -0.11 & -0.02 & 0.13 & 0.25 & 0.02 \\
\hline & Eppley & 0.03 & 0.23 & 0.15 & -0.09 & 0.36 \\
\hline & CbPM & 0.00 & 0.37 & -0.15 & -0.40 & 0.44 \\
\hline \multirow[t]{3}{*}{ NCRS } & VGPM & -0.14 & 0.05 & -0.04 & 0.39 & -0.06 \\
\hline & Eppley & -0.11 & 0.29 & -0.01 & -0.04 & 0.22 \\
\hline & $\mathrm{CbPM}$ & -0.14 & 0.38 & -0.24 & -0.29 & 0.34 \\
\hline \multirow[t]{3}{*}{ SCRS } & VGPM & -0.25 & 0.12 & 0.10 & 0.41 & -0.04 \\
\hline & Eppley & -0.29 & 0.08 & 0.08 & 0.40 & -0.05 \\
\hline & $\mathrm{CbPM}$ & -0.36 & 0.14 & 0.04 & -0.12 & 0.13 \\
\hline \multirow[t]{3}{*}{ SRS } & VGPM & -0.32 & 0.11 & 0.05 & 0.16 & 0.02 \\
\hline & Eppley & -0.36 & 0.15 & 0.10 & 0.16 & 0.08 \\
\hline & $\mathrm{CbPM}$ & -0.23 & -0.06 & -0.25 & 0.07 & 0.07 \\
\hline
\end{tabular}


This result can help to explain the extreme low NPP of CbPM in Fig. 7. These abnormal NPP values may result from the increased MLD-caused substantially lowered $f(E)$ in (15) and altered value of $P A R_{M L}$ in (12) and (13). Besides, the low NPP values may also be calculated from inputs of $b_{b p}$ lower than the particle backscattering coefficient of non-algal particles ( $b_{b p}$ NAP) of $0.00035 \mathrm{~m}-1$ in (10), where $b_{b p}$ was modified to $0.00036 \mathrm{~m}-1$. This implies that the $b_{b p}$ NAP in the Red Sea is not constant but occasionally lower than $0.00035 \mathrm{~m}-1$. The CbPM model assumes the $b_{b p}$ NAP as the stable heterotrophic and detrital components of the surface particles that does not covary with Chla and it is constant in both space and time [13]. However, recent studies suggested $b_{b p}$ NAP to be highly dynamic and dependent on the season and biogeochemistry of the area [90]-[93]. Bellacicco et al. [93] estimated the median $b_{b p}$ NAP value of global ocean as $0.00095 \mathrm{~m}-1$, thus highlighting that the difference (of around a factor of 2) by using spatial $b_{b p}$ NAP variable rather than a constant value in the phytoplankton carbon biomass estimation. In their Figure 2.c, the central Red Sea was marked with high percentage of $b_{b p}$ NAP (> 60\%) of the total $b_{b p}$. The estimation of phytoplankton carbon biomass from constant $b_{b p}$ NAP value $(0.00035 \mathrm{~m}-1)$ is over twice as much as the biomass estimated using spatially resolved $b_{b p}$ NAP (their Figure 3.b). This could be explained that the nutrient limitation results in rapid recycling of low phytoplankton biomass in the surface layer, which supports higher bacterial, small heterotrophic, and detrital biomass [94]. In the later research, the in situ datasets from Biogeochemical-Argo (aka BGC-Argo) floats were used to observe the $b_{b p}$ NAP in global overview [95]. The study revealed two distinct oceanic conditions in terms of Chla signals: "photoacclimation-dominance" and "biomassdominance". The former is typical of oligotrophic areas (e.g. Red Sea) shows the variability of Chla is uncoupled with biomass but driven by the process of photoacclimation [94], [96], [97]. The latter case is typical of most productive regions with high $b_{b p}$ and Chla co-variability. It further confirmed the high surface $b_{b p}$ NAP percentage $(>80 \%)$ in the less productive areas that pico- and nano-phytoplankton dominated communities [98], which can be rapidly recycled. Consequently, the optimization of phytoplankton carbon models (e.g. CbPM) using the spatial-temporal and depth $b_{b p}$ NAP variables is suggested to improve their modeling performance from remote sensing observations [99].

As demonstrated in Table II, VGPM and Eppley NPP at BATS are correlated to the NPGO but not correlated to MEI and PDO. By contrast, the CbPM NPP is negatively correlated to the NPGO but positively correlated to MEI and PDO. At HOT, the ENSO or PDO-related events affect the stratification and nutrient supply to alter the NPP. This may shed some light on the VGPM and Eppley NPP blooms in the NCRS during the strong El Niño 1997-1998 season. This indicates that VGPM and Eppley are more reliable than CbPM for the Red Sea NPP investigation. However, SST as a surface physical field fails to show a clear relationship with depth-integrated NPP comparing to deeper physical fields, while both models substantially rely on the $P_{o p t}^{B}$ estimated with SST function. The ocean color models usually pay little attention to the contribution from the deep-layer related NPP, which explains the underestimation of the NPP in both HOT and BATS. Further research has examined the performance of satellite NPP models in coastal and pelagic regions across the globe, including the Mediterranean Sea and the Arabian Sea adjacent to the Red Sea [25]. Interestingly, this study concluded that the model skill evaluated by the root-mean square difference (RSMD) was lowest in the Mediterranean Sea $(0.42 \pm 0.06)$ and intermediate in the Arabian Sea $(0.22 \pm 0.09)$. The Eppley model achieved the best estimate (RSMD < 0.15) in the Arabian Sea. However, the different NPP trends between VGPM/Eppley and CbPM in SRS (Fig. 7) casts doubt on the ability of models using satellitederived data to estimate the magnitude and the trends of NPP over multi-decadal or shorter time periods, which was also demonstrated at HOT and BATS [25], [26]. The NPP values estimated and agreed upon by all three models in the SCRS and SRS are exponentially higher than those in the NCRS and NRS. There are several possibilities for such differences: 1) The phytoplankton growth is promoted from the nutrient water obtained from GA exchange or eddies' upwelling near SCRS and SRS [32]; 2) dust deposition in this region could supply nutrients and prompt the phytoplankton growth, yet the presence of high atmospheric content of aerosol particles complicates atmospheric correction and limits the data availability [39]; in addition, the dust particles in the water surface can also alter the inherent optical properties (IOPs) such as $\left.b_{b p} ; 3\right)$ the sample points collected towards the south of the Red Sea, especially in the SRS, are closer to the coastal areas. This may result in the uncertainty of remotely sensed ocean color data such as Chla and Chla: $C_{\text {sat }}$, because their ocean color signatures may possibly be influenced by different coastal gradients.

It is also important to note that the performance of these three models is primarily dependent on the validity of input variables, derived from ocean color remote sensors (e.g. Chla, $b_{b p}$, SST and PAR), or even model simulations (MLD) (equation (15)). Additionally, it is also challenging to decide the parameters used in the NPP models, which require more regional in situ measurements. For example, the empirical parameters $\left(c_{1}\right.$ and $c_{2}$ ) in (6) were calculated from thousands of field measurements, but not specifically for the Red Sea. It is worth mentioning that the inherent optical properties (absorption and scattering) and apparent optical properties ( $\mathrm{R}_{\mathrm{rs}}$ and KD) of the Red Sea is not well documented. Also the development and validation of regional optical algorithms are lacking for the Red Sea.

Beside carbon-based and chlorophyll-based production models, the phytoplankton absorption-based model or IOPbased production model, recently resulted in more PP studies on a global scale [7], [79], [80], [100]. It was noted that the absorption by phytoplankton pigments was a preferred 
parameter than pigment biomass for NPP retrievals [101]. This parameter was also regarded as better than SST to represent the photosynthetic rate of VGPM model in the Southern Sea [100]. As a good indicator of phytoplankton growth, KD490 can show short-term phytoplankton blooms and physical processes (anticyclonic and cyclonic eddies) in the Red Sea [102]. The absorption-based models using remotely sensed data could minimize the impacts of pigment packaging, colored dissolved organic matter (CDOM), and non-algal matter, in order to reach both lower bias and higher standard deviation evaluated by in situ datasets in the Arctic Ocean [103].

The rapid increase of SST was observed in all the regions of the Red Sea (Fig. 8), while its impact on NPP should be considered as one of the most crucial factors. As it is illustrated in Fig. 5c, the most apparent disagreement between VGPM and Eppley lies in the response of the photosynthetic rate to the temperature, expressed by $P_{o p t}^{B}$. The VGPM NPP shows a growth with increasing temperature until reaching a maximum at $20{ }^{\circ} \mathrm{C}$, followed by a decrease at higher temperatures. This mechanism is based on the connection between nutrient limitation and warmer waters in the ocean [14], [45]. The NPP at BATS demonstrated an annual increase of $10.08 \mathrm{mg} \mathrm{C} \mathrm{m-2}$ day-1 year-1, with no significant increase of SST during 1988 to 2006, yet the HOT region had a similar increase of $10.23 \mathrm{mg} \mathrm{C}$ m-2 day-1 year-1 but with noted SST increase of $0.06{ }^{\circ} \mathrm{C}$ year -1 . The decreased wind-forcing in the SCRS and SRS may lessen the MLD, which in turn limit the availability of nutrients in the euphotic zone [26]. The frequent dust events covering the water surface also help lower the SST while blocking observations from ocean color satellites. Even though natural variations, such as a swing back to wetter phases of the Pacific Decadal Oscillation (PDO) and the El Niño/Southern Oscillation (ENSO) patterns, may temporarily relieve drought conditions and reduce the frequency of dust storms currently plaguing the Arabian Peninsula, long-term climate models indicate temperatures in the region will continue to rise and the observed drying trend will continue, leading to an overall increase in the number of significant regional dust events [104].

In conclusion, the three global NPP models used for deriving the satellite NPP products were evaluated in the Red Sea region. Models' intercomparison were performed using 8-day composite and monthly averages during the 1998-2018 period using different statistical methodologies. The estimated NPP using VGPM and Eppley significantly correlated well with the environmental and atmospheric variables allowing for accurate estimation of NPP as compared to CbPM, which performed poorly. This poor performance of the CbPM originates from the input variables (i.e., $b_{b p}, b_{b p} \mathrm{NAP}$ and $\left.\mathrm{KD} 490\right)$ )) that are not well parameterized for this region and require further refinement using comprehensive local optical measurements. The models' intercomparison are further performed by the correlation maps presented in the Fig. 6 concerning the coherency between the same NPP products calculated from different sensors.

Findings of this study could help the ocean color community and modelers to make a better choice among different PP models and associated satellite products for the Red Sea region, where chlorophyll concentrations are typically low. Moreover, this work elaborates on our previous findings in [39], [41] of possible dust impact on the marine PP and nutrient's supply affecting NPP.

Since the Red Sea is one of the warmest and saltiest ecosystems, it qualifies to be an ideal natural laboratory to study the physiological responses of phytoplankton community in such harsh conditions. The Red Sea could be a precursor to predict the behavior of the phytoplankton groups to nutrient variations, as well as to manifest the effects of global warming in other regions. Consequently, it requires further data at wider spatial and temporal scales and development of region specific NPP algorithms for future advances.

\section{REFERENCES}

[1] M. J. Behrenfeld, "Biospheric Primary Production During an ENSO Transition," Science, vol. 291, no. 5513, pp. 2594-2597, Mar. 2001.

[2] P. G. Falkowski, "Biogeochemical Controls and Feedbacks on Ocean Primary Production," Science, vol. 281, no. 5374, pp. 200-206, Jul. 1998.

[3] A. A. Bianchi, "Vertical stratification and air-sea $\mathrm{CO}_{2}$ fluxes in the Patagonian shelf," Journal of Geophysical Research, vol. 110, no. C7, 2005.

[4] M.-E. Carr et al., "A comparison of global estimates of marine primary production from ocean color," Deep Sea Research Part II: Topical Studies in Oceanography, vol. 53, no. 5-7, pp. 741-770, Mar. 2006.

[5] S. Milutinović and L. Bertino, "Assessment and propagation of uncertainties in input terms through an ocean-color-based model of primary productivity," Remote Sensing of Environment, vol. 115, no. 8, pp. 1906-1917, Aug. 2011.

[6] W. E. Esaias et al., "An overview of MODIS capabilities for ocean science observations," IEEE Transactions on Geoscience and Remote Sensing, vol. 36, no. 4, pp. 1250-1265, Jul. 1998.

[7] S. Ma et al., "Estimation of Marine Primary Productivity From Satellite-Derived Phytoplankton Absorption Data," IEEE Journal of Selected Topics in Applied Earth Observations and Remote Sensing, vol. 7, no. 7, pp. 3084-3092, Jul. 2014.

[8] R. Y. Setiawan and A. Habibi, "Satellite Detection of Summer Chlorophyll-a Bloom in the Gulf of Tomini," IEEE Journal of Selected Topics in Applied Earth Observations and Remote Sensing, vol. 4, no. 4, pp. 944948, Dec. 2011.

[9] R. Y. Setiawan and H. Kawamura, "Summertime Phytoplankton Bloom in the South Sulawesi Sea," IEEE Journal of Selected Topics in Applied Earth Observations and Remote Sensing, vol. 4, no. 1, pp. 241244, Mar. 2011.

[10] Z. Lee, J. Marra, M. J. Perry, and M. Kahru, "Estimating oceanic primary productivity from ocean color remote 
sensing: A strategic assessment," Journal of Marine Systems, vol. 149, pp. 50-59, Sep. 2015.

[11] Z. Lee, J. Marra, M. J. Perry, and M. Kahru, "Estimating oceanic primary productivity from ocean color remote sensing: A strategic assessment," Journal of Marine Systems, vol. 149, pp. 50-59, Sep. 2015.

[12] D. Antoine and A. Morel, "Oceanic primary production: 1. Adaptation of a spectral light-photosynthesis model in view of application to satellite chlorophyll observations," Global Biogeochemical Cycles, vol. 10, no. 1, pp. 43-55, Mar. 1996.

[13] M. J. Behrenfeld, E. Boss, D. A. Siegel, and D. M. Shea, "Carbon-based ocean productivity and phytoplankton physiology from space," Global Biogeochemical Cycles, vol. 19, no. 1, Mar. 2005.

[14] M. J. Behrenfeld and P. G. Falkowski, "A consumer's guide to phytoplankton primary productivity models," Limnology and Oceanography, vol. 42, no. 7, pp. 14791491, Nov. 1997.

[15] J. Campbell et al., "Comparison of algorithms for estimating ocean primary production from surface chlorophyll, temperature, and irradiance," Global Biogeochemical Cycles, vol. 16, no. 3, pp. 9-1-9-15, Sep. 2002.

[16] R. W. Eppley, E. Stewart, M. R. Abbott, and U. Heyman, "Estimating ocean primary production from satellite chlorophyll. Introduction to regional differences and statistics for the Southern California Bight," Journal of Plankton Research, vol. 7, no. 1, pp. 57-70, 1985.

[17] R. L. Iverson, W. E. Esaias, and K. Turpie, "Ocean annual phytoplankton carbon and new production, and annual export production estimated with empirical equations and CZCS data," Global Change Biology, vol. 6, no. 1, pp. 57-72, Jan. 2000.

[18] A. Longhurst, S. Sathyendranath, T. Platt, and C. Caverhill, "An estimate of global primary production in the ocean from satellite radiometer data," Journal of Plankton Research, vol. 17, no. 6, pp. 1245-1271, 1995.

[19] M. E. Ondrusek, R. R. Bidigare, K. Waters, and D. M. Karl, "A predictive model for estimating rates of primary production in the subtropical North Pacific Ocean," Deep Sea Research Part II: Topical Studies in Oceanography, vol. 48, no. 8-9, pp. 1837-1863, Jan. 2001.

[20] T. Platt et al., "Operational estimation of primary production at large geographical scales," Remote Sensing of Environment, vol. 112, no. 8, pp. 3437-3448, Aug. 2008.

[21] T. Platt and S. Sathyendranath, "Estimators of primary production for interpretation of remotely sensed data on ocean color," Journal of Geophysical Research, vol. 98, no. C8, p. $14561,1993$.

[22] T. Westberry, M. J. Behrenfeld, D. A. Siegel, and E. Boss, "Carbon-based primary productivity modeling with vertically resolved photoacclimation," Global Biogeochemical Cycles, vol. 22, no. 2, p. n/a-n/a, Jun. 2008.

[23] M. A. M. Friedrichs et al., "Assessing the uncertainties of model estimates of primary productivity in the tropical
Pacific Ocean," Journal of Marine Systems, vol. 76, no. 1-2, pp. 113-133, Feb. 2009.

[24] C. R. McClain et al., "Satellite ocean-color observations of the tropical Pacific Ocean," Deep Sea Research Part II: Topical Studies in Oceanography, vol. 49, no. 13-14, pp. 2533-2560, Jan. 2002.

[25] V. S. Saba et al., "An evaluation of ocean color model estimates of marine primary productivity in coastal and pelagic regions across the globe," Biogeosciences, vol. 8, no. 2, pp. 489-503, Feb. 2011.

[26] V. S. Saba et al., "Challenges of modeling depthintegrated marine primary productivity over multiple decades: A case study at BATS and HOT," Global Biogeochemical Cycles, vol. 24, no. 3, p. n/a-n/a, Sep. 2010.

[27] M. A. B. Qurban, M. Wafar, and M. Heinle, "Phytoplankton and Primary Production in the Red Sea," in Oceanographic and Biological Aspects of the Red Sea, N. M. A. Rasul and I. C. F. Stewart, Eds. Cham: Springer International Publishing, 2019, pp. 491-506.

[28] M. A. Qurban, M. Wafar, R. Jyothibabu, and K. P. Manikandan, "Patterns of primary production in the Red Sea," Journal of Marine Systems, vol. 169, pp. 87-98, May 2017.

[29] M. A. Qurban, A. C. Balala, S. Kumar, P. S. Bhavya, and M. Wafar, "Primary production in the northern Red Sea," Journal of Marine Systems, vol. 132, pp. 75-82, Apr. 2014.

[30] M. Wafar, M. Ashraf, K. P. Manikandan, M. A. Qurban, and Y. Kattan, "Propagation of Gulf of Aden Intermediate Water (GAIW) in the Red Sea during autumn and its importance to biological production," Journal of Marine Systems, vol. 154, pp. 243-251, Feb. 2016.

[31] M. Wafar, M. A. Qurban, M. Ashraf, K. P. Manikandan, A. V. Flandez, and A. C. Balala, "Patterns of distribution of inorganic nutrients in Red Sea and their implications to primary production," Journal of Marine Systems, vol. 156, pp. 86-98, Apr. 2016.

[32] D. A. Smeed, "Exchange through the Bab el Mandab," Deep Sea Research Part II: Topical Studies in Oceanography, vol. 51, no. 4-5, pp. 455-474, Feb. 2004.

[33] P. Zhan, A. C. Subramanian, F. Yao, and I. Hoteit, "Eddies in the Red Sea: A statistical and dynamical study," Journal of Geophysical Research: Oceans, vol. 119, no. 6, pp. 3909-3925, Jun. 2014.

[34] K. Grasshoff, "The hydrochemistry of landlocked basins and fjords," Chemical oceanography, vol. 2, pp. 455597, 1975.

[35] D. E. Pedgley, "An outline of the weather and climate of the Red Sea," L'Oceanographie Physique de la Mer Rouge, pp. 9-27, 1974.

[36] E. A. Shaikh, J. C. Roff, and N. M. Dowidar, "Phytoplankton ecology and production in the Red Sea off Jiddah, Saudi Arabia," Marine Biology, vol. 92, no. 3, pp. 405-416, Aug. 1986.

[37] M. L. Berumen et al., "The status of coral reef ecology research in the Red Sea," Coral Reefs, vol. 32, no. 3, pp. 737-748, Sep. 2013. 
[38] N. E. Cantin, A. L. Cohen, K. B. Karnauskas, A. M. Tarrant, and D. C. McCorkle, "Ocean Warming Slows Coral Growth in the Central Red Sea," Science, vol. 329, no. 5989, pp. 322-325, Jul. 2010.

[39] W. Li et al., "An Assessment of Atmospheric and Meteorological Factors Regulating Red Sea Phytoplankton Growth," Remote Sensing, vol. 10, no. 5, p. 673, Apr. 2018.

[40] D. E. Raitsos et al., "Sensing coral reef connectivity pathways from space," Scientific Reports, vol. 7, no. 1, Dec. 2017.

[41] W. Li, H. El-Askary, K. ManiKandan, M. Qurban, M. Garay, and O. Kalashnikova, "Synergistic Use of Remote Sensing and Modeling to Assess an Anomalously High Chlorophyll-a Event during Summer 2015 in the South Central Red Sea," Remote Sensing, vol. 9, no. 8, p. 778, Jul. 2017.

[42] D. E. Raitsos, Y. Pradhan, R. J. W. Brewin, G. Stenchikov, and I. Hoteit, "Remote Sensing the Phytoplankton Seasonal Succession of the Red Sea," PLoS ONE, vol. 8, no. 6, p. e64909, Jun. 2013.

[43] D. Dreano, D. E. Raitsos, J. Gittings, G. Krokos, and I. Hoteit, "The Gulf of Aden Intermediate Water Intrusion Regulates the Southern Red Sea Summer Phytoplankton Blooms," PLOS ONE, vol. 11, no. 12, p. e0168440, Dec. 2016.

[44] H. Brindley et al., "An assessment of the quality of aerosol retrievals over the Red Sea and evaluation of the climatological cloud-free dust direct radiative effect in the region," Journal of Geophysical Research: Atmospheres, vol. 120, no. 20, pp. 10,862-10,878, Oct. 2015.

[45] M. J. Behrenfeld and P. G. Falkowski, "Photosynthetic rates derived from satellite-based chlorophyll concentration," Limnology and Oceanography, vol. 42, no. 1, pp. 1-20, Jan. 1997.

[46] A. Morel, "Light and marine photosynthesis: a spectral model with geochemical and climatological implications," Progress in Oceanography, vol. 26, no. 3, pp. 263-306, Jan. 1991.

[47] M. J. Behrenfeld and E. Boss, "Beam attenuation and chlorophyll concentration as alternative optical indices of phytoplankton biomass," Journal of Marine Research, vol. 64, no. 3, pp. 431-451, May 2006.

[48] M. J. Behrenfeld and E. Boss, "The beam attenuation to chlorophyll ratio: an optical index of phytoplankton physiology in the surface ocean?," Deep Sea Research Part I: Oceanographic Research Papers, vol. 50, no. 12, pp. 1537-1549, Dec. 2003.

[49] M. D. Durand and R. J. Olson, "Contributions of phytoplankton light scattering and cell concentration changes to diel variations in beam attenuation in the equatorial Pacific from flow cytometric measurements of pico-, ultra- and nanoplankton," Deep Sea Research Part II: Topical Studies in Oceanography, vol. 43, no. 4-6, pp. 891-906, Jan. 1996.

[50] R. E. Green, H. M. Sosik, and R. J. Olson, “Contributions of phytoplankton and other particles to inherent optical properties in New England continental shelf waters,"
Limnology and Oceanography, vol. 48, no. 6, pp. 23772391, Nov. 2003.

[51] R. E. Green and H. M. Sosik, "Analysis of apparent optical properties and ocean color models using measurements of seawater constituents in New England continental shelf surface waters," Journal of Geophysical Research: Oceans, vol. 109, no. C3, Mar. 2004.

[52] H. Loisel, E. Bosc, D. Stramski, K. Oubelkheir, and P.Y. Deschamps, "Seasonal variability of the backscattering coefficient in the Mediterranean Sea based on satellite SeaWiFS imagery," Geophysical Research Letters, vol. 28, no. 22, pp. 4203-4206, Nov. 2001.

[53] D. Stramski, "Estimation of Particulate Organic Carbon in the Ocean from Satellite Remote Sensing," Science, vol. 285, no. 5425, pp. 239-242, Jul. 1999.

[54] S. A. Garver and D. A. Siegel, "Inherent optical property inversion of ocean color spectra and its biogeochemical interpretation: 1. Time series from the Sargasso Sea," Journal of Geophysical Research: Oceans, vol. 102, no. C8, pp. 18607-18625, Aug. 1997.

[55] S. Maritorena, D. A. Siegel, and A. R. Peterson, "Optimization of a semianalytical ocean color model for global-scale applications," Applied Optics, vol. 41, no. 15, p. 2705, May 2002.

[56] D. A. Siegel, S. Maritorena, N. B. Nelson, D. A. Hansell, and M. Lorenzi-Kayser, "Global distribution and dynamics of colored dissolved and detrital organic materials," Journal of Geophysical Research: Oceans, vol. 107, no. C12, pp. 21-1-21-14, Dec. 2002.

[57] K. L. Carder, F. R. Chen, J. P. Cannizzaro, J. W. Campbell, and B. G. Mitchell, "Performance of the MODIS semi-analytical ocean color algorithm for chlorophyll-a," Advances in Space Research, vol. 33, no. 7, pp. 1152-1159, Jan. 2004.

[58] K. L. Carder, F. R. Chen, Z. P. Lee, S. K. Hawes, and D. Kamykowski, "Semianalytic Moderate-Resolution Imaging Spectrometer algorithms for chlorophyll $a$ and absorption with bio-optical domains based on nitratedepletion temperatures," Journal of Geophysical Research: Oceans, vol. 104, no. C3, pp. 5403-5421, Mar. 1999.

[59] K. L. Carder, S. K. Hawes, K. A. Baker, R. C. Smith, R. G. Steward, and B. G. Mitchell, "Reflectance model for quantifying chlorophyll $a$ in the presence of productivity degradation products," Journal of Geophysical Research, vol. 96, no. C11, p. 20599, 1991.

[60] F. E. Hoge and P. E. Lyon, "Satellite retrieval of inherent optical properties by linear matrix inversion of oceanic radiance models: An analysis of model and radiance measurement errors," Journal of Geophysical Research: Oceans, vol. 101, no. C7, pp. 16631-16648, Jul. 1996.

[61] Z. Lee, K. L. Carder, and R. A. Arnone, "Deriving inherent optical properties from water color: a multiband quasi-analytical algorithm for optically deep waters," Applied Optics, vol. 41, no. 27, p. 5755, Sep. 2002.

[62] Z. P. Lee, K. L. Carder, R. G. Steward, T. G. Peacock, C. O. Davis, and J. S. Patch, "An empirical algorithm for light absorption by ocean water based on color," Journal 
of Geophysical Research: Oceans, vol. 103, no. C12, pp. 27967-27978, Nov. 1998.

[63] Z. Lee and K. L. Carder, "Absorption spectrum of phytoplankton pigments derived from hyperspectral remote-sensing reflectance," Remote Sensing of Environment, vol. 89, no. 3, pp. 361-368, Feb. 2004.

[64] C. S. Roesler and M. J. Perry, "In situ phytoplankton absorption, fluorescence emission, and particulate backscattering spectra determined from reflectance," Journal of Geophysical Research, vol. 100, no. C7, p. 13279, 1995.

[65] T. J. Smyth, G. F. Moore, T. Hirata, and J. Aiken, "Semianalytical model for the derivation of ocean color inherent optical properties: description, implementation, and performance assessment," Applied Optics, vol. 45, no. 31, p. 8116, Nov. 2006.

[66] S. Maritorena and D. A. Siegel, "Consistent merging of satellite ocean color data sets using a bio-optical model," Remote Sensing of Environment, vol. 94, no. 4, pp. 429440, Feb. 2005.

[67] MODIS ATBD: http://modisatmos.gsfc.nasa.gov/MOD06_L2/atbd.html (accessed December 2018) .

[68] MERIS

ATBD: http://envisat.esa.int/handbooks/meris/CNTR2-7.html (accessed October 2018) .

[69] W. M. Balch, "Calcium carbonate measurements in the surface global ocean based on Moderate-Resolution Imaging Spectroradiometer data," Journal of Geophysical Research, vol. 110, no. C7, 2005.

[70] H. R. Gordon, G. C. Boynton, W. M. Balch, S. B. Groom, D. S. Harbour, and T. J. Smyth, "Retrieval of coccolithophore calcite concentration from SeaWiFS Imagery," Geophysical Research Letters, vol. 28, no. 8, pp. 1587-1590, Apr. 2001.

[71] D. Stramski et al., "Relationships between the surface concentration of particulate organic carbon and optical properties in the eastern South Pacific and eastern Atlantic Oceans," Biogeosciences, vol. 5, no. 1, pp. 171201, Feb. 2008.

[72] H. R. Gordon, "Atmospheric correction of ocean color imagery in the Earth Observing System era," Journal of Geophysical Research: Atmospheres, vol. 102, no. D14, pp. 17081-17106, Jul. 1997.

[73] Frouin, R., B. A. Franz, and P. J. Werdell, 2003: The SeaWiFS PAR product. In Algorithm Updates for the Fourth SeaWiFS Data Reprocessing, S. B. Hooker and E. R. Firestone, Editors, CC NASA/TM- 2003-206892, Vol. 22, 46-50.

[74] A. Morel, Y. Huot, B. Gentili, P. J. Werdell, S. B. Hooker, and B. A. Franz, "Examining the consistency of products derived from various ocean color sensors in open ocean (Case 1) waters in the perspective of a multisensor approach," Remote Sensing of Environment, vol. 111, no. 1, pp. 69-88, Nov. 2007.

[75] R. Bleck, "An oceanic general circulation model framed in hybrid isopycnic-Cartesian coordinates," Ocean Modelling, vol. 4, no. 1, pp. 55-88, Jan. 2002.
[76] G. Modeling, “MERRA-2 tavgM_2d_aer_Nx: 2d,Monthly mean,Time-averaged,SingleLevel,Assimilation,Aerosol Diagnostics V5.12.4." NASA Goddard Earth Sciences Data and Information Services Center, 2015.

[77] G. Modeling, "MERRA-2 tavgM_2d_flx_Nx: 2d,Monthly mean,Time-Averaged,SingleLevel,Assimilation,Surface Flux Diagnostics V5.12.4." NASA Goddard Earth Sciences Data and Information Services Center, 2015.

[78] H. Claustre, "Toward a taxon-specific parameterization of bio-optical models of primary production: A case study in the North Atlantic," Journal of Geophysical Research, vol. 110, no. C7, 2005.

[79] J. Marra, C. C. Trees, and J. E. O'Reilly, "Phytoplankton pigment absorption: A strong predictor of primary productivity in the surface ocean," Deep Sea Research Part I: Oceanographic Research Papers, vol. 54, no. 2, pp. 155-163, Feb. 2007.

[80] M. J. Oliver, "Deriving in situ phytoplankton absorption for bio-optical productivity models in turbid waters," Journal of Geophysical Research, vol. 109, no. C7, 2004.

[81] OC-CCI dataset: https://esa-oceancolour-cci.org/ (accessed October 2018).

[82] F. G. Taboada, A. D. Barton, C. A. Stock, J. Dunne, and J. G. John, "Seasonal to interannual predictability of oceanic net primary production inferred from satellite observations," Progress in Oceanography, vol. 170, pp. 28-39, Jan. 2019.

[83] M. Gómez-Letona, A. G. Ramos, J. Coca, and J. Arístegui, "Trends in Primary Production in the Canary Current Upwelling System-A Regional Perspective Comparing Remote Sensing Models," Frontiers in Marine Science, vol. 4, Nov. 2017.

[84] WMO Statement on the State of the Global Climate in 2017. Available online: https://public.wmo.int/en/wmostatement-state-of-global-climate-2017 (accessed on 18 May 2018).

[85] WMO Statement on the State of the Global Climate in 2018. Available online: https://public.wmo.int/en/ourmandate/climate/wmo-statement-state-of-global-climate (accessed on 18 May 2019).

[86] W. Zhou, "Zone statistics of the oceanic primary productivity for the traditional fishing areas of the open South China Sea based on MODIS products," Applied Ecology and Environmental Research, vol. 15, no. 3, pp. 1013-1024, 2017.

[87] S. Milutinović, M. J. Behrenfeld, J. A. Johannessen, and T. Johannessen, "Sensitivity of remote sensing-derived phytoplankton productivity to mixed layer depth: Lessons from the carbon-based productivity model: OCEAN PRODUCTIVITY AND MIXED LAYER DEPTH," Global Biogeochemical Cycles, vol. 23, no. 4, p. n/a-n/a, Dec. 2009.

[88] D. J. McGillicuddy et al., "Eddy/Wind Interactions Stimulate Extraordinary Mid-Ocean Plankton Blooms," Science, vol. 316, no. 5827, pp. 1021-1026, May 2007.

[89] A. Cianca, P. Helmke, B. Mouriño, M. J. Rueda, O. Llinás, and S. Neuer, "Decadal analysis of hydrography 
and in situ nutrient budgets in the western and eastern North Atlantic subtropical gyre," Journal of Geophysical Research, vol. 112, no. C7, Jul. 2007.

[90] I. Siokou-Frangou et al., "Plankton in the open Mediterranean Sea: a review," Biogeosciences, vol. 7, no. 5, pp. 1543-1586, May 2010.

[91] D. Antoine et al., "Variability in optical particle backscattering in contrasting bio-optical oceanic regimes," Limnol. Oceanogr., vol. 56, no. 3, pp. 955973, May 2011.

[92] M. Bellacicco, G. Volpe, S. Colella, J. Pitarch, and R. Santoleri, "Influence of photoacclimation on the phytoplankton seasonal cycle in the Mediterranean Sea as seen by satellite," Remote Sensing of Environment, vol. 184, pp. 595-604, Oct. 2016.

[93] M. Bellacicco et al., "Global Distribution of Non-algal Particles From Ocean Color Data and Implications for Phytoplankton Biomass Detection," Geophys. Res. Lett., vol. 45, no. 15, pp. 7672-7682, Aug. 2018.

[94] M. Barbieux et al., "Assessing the Variability in the Relationship Between the Particulate Backscattering Coefficient and the Chlorophyll $a$ Concentration From a Global Biogeochemical-Argo Database," J. Geophys. Res. Oceans, vol. 123, no. 2, pp. 1229-1250, Feb. 2018.

[95] M. Bellacicco et al., "Global Variability of Optical Backscattering by Non-algal particles From a Biogeochemical-Argo Data Set," Geophys. Res. Lett., vol. 46, no. 16, pp. 9767-9776, Aug. 2019.

[96] D. A. Siegel et al., "Regional to global assessments of phytoplankton dynamics from the SeaWiFS mission," Remote Sensing of Environment, vol. 135, pp. 77-91, Aug. 2013.

[97] K. H. Halsey and B. M. Jones, "Phytoplankton Strategies for Photosynthetic Energy Allocation," Annu. Rev. Mar. Sci., vol. 7, no. 1, pp. 265-297, Jan. 2015.

[98] A. Mignot, H. Claustre, J. Uitz, A. Poteau, F. D’Ortenzio, and X. Xing, "Understanding the seasonal dynamics of phytoplankton biomass and the deep chlorophyll maximum in oligotrophic environments: A Bio-Argo float investigation," Global Biogeochem. Cycles, vol. 28, no. 8, pp. 856-876, Aug. 2014.

[99] V. Martínez-Vicente et al., "Intercomparison of Ocean Color Algorithms for Picophytoplankton Carbon in the Ocean," Front. Mar. Sci., vol. 4, p. 378, Dec. 2017.

[100] T. Hirawake, S. Takao, N. Horimoto, T. Ishimaru, Y. Yamaguchi, and M. Fukuchi, "A phytoplankton absorption-based primary productivity model for remote sensing in the Southern Ocean," Polar Biology, vol. 34, no. 2, pp. 291-302, Feb. 2011.

[101] Z. P. Lee, K. L. Carder, J. Marra, R. G. Steward, and M. J. Perry, "Estimating primary production at depth from remote sensing," Applied Optics, vol. 35, no. 3, p. 463, Jan. 1996.

[102] S. P. Tiwari, Y. V. B. Sarma, B. Kurten, M. Ouhssain, and B. H. Jones, "An Optical Algorithm to Estimate Downwelling Diffuse Attenuation Coefficient in the Red Sea," IEEE Transactions on Geoscience and Remote Sensing, vol. 56, no. 12, pp. 7174-7182, Dec. 2018.
[103] Y. J. Lee et al., “An assessment of phytoplankton primary productivity in the Arctic Ocean from satellite ocean color/in situ chlorophyll- $a$ based models: ARCTIC PRIMARY PRODUCTIVITY ROUND ROBIN," Journal of Geophysical Research: Oceans, vol. 120, no. 9, pp. 6508-6541, Sep. 2015.

[104] M. Notaro, Y. Yu, and O. V. Kalashnikova, "Regime shift in Arabian dust activity, triggered by persistent Fertile Crescent drought: REGIME SHIFT IN ARABIAN DUST," Journal of Geophysical Research: Atmospheres, vol. 120, no. 19, pp. 10,229-10,249, Oct. 2015.

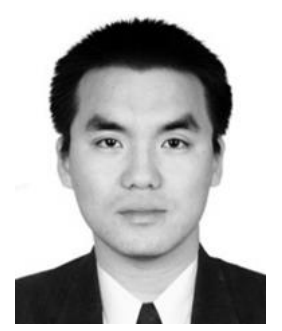

Wenzhao Li received the B.S. degree in Software and Digital Media Engineering from Shandong University, China in 2011. He received M.S. degree in Telecom and Computer Networking from Northeastern University, Boston, MA, USA in 2014. He is currently working toward the Ph.D. degree in computational and data sciences at Chapman University, CA, USA. His research interests include remote sensing, oceanography, artificial intelligence and big data analysis. He has published more than 10 publications including peer-reviewed papers, full conference proceedings, and presented in international conferences such as AGU and EGU. He is a peer reviewer for several international journals such as Marine Pollution Bulletin and others.

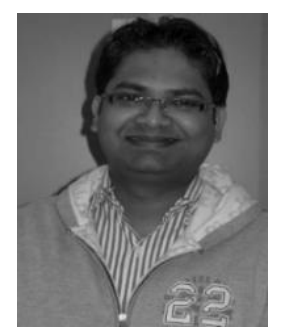

Surya Prakash Tiwari received the B.Sc. degree in Mathematics and Physics, M.Sc. degree in Physics with specialization in Electronics from Gorakhpur University, India, in 2005 and 2007 respectively. Subsequently, he received M.Tech. degree in Remote Sensing and GIS from SRM University, Chennai, India in 2009. He received the Ph.D. degree in Optical Remote Sensing from Indian Institute of Technology Madras (IITM), Chennai, India, 2013. From 2013 to 2014, he was a postdoctoral research associate at the City College of City University of New York, USA. From 2014 to 2017 he was a Postdoctoral fellow in the Biological and Environmental Science and Engineering Division, Red Sea Research Center, King Abdullah University of Science and Technology (KAUST), Thuwal, Saudi Arabia. Since 2018 he is working as a Research Scientist III (Assistant Professor) in the Center for Environment \& Water, King Fahd University of Petroleum and Minerals (KFUPM), Dhahran, Saudi Arabia. His research interest includes the bio-geo-optics, ocean color remote sensing, radiative transfer theory, underwater visibility, phytoplankton blooms, primary productivity, instrument design, and other subdisciplines. He has been involved in studying optics and remote sensing of the Red Sea. He has published more than 20 publications including peer-reviewed papers, full conference proceedings, and other conference papers. He is a peer reviewer for several international journals such as Remote Sensing of Environment, Ocean Science, IEEE Transaction on 
Geosciences and Remote Sensing and others. He was a recipient of the IOCCG Scholarship for the IOCCG Summer Lecture Series in 2014.

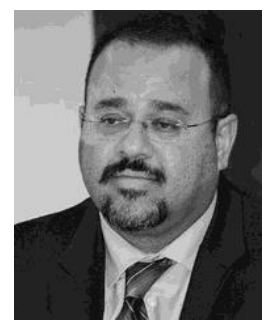

Hesham Mohamed El-Askary received the B.S. degree in Physics with focus on Geophysics from Alexandria University, Alexandria, Egypt, in 1994. He received his two M.S. degrees in Earth Systems Science and Computational Science and Informatics as well as his Ph.D. with focus on Environmental Physics, from George Mason University, Virginia, USA in 2003 and 2004 respectively. Since 2008 he has been with the Schmid College of Science and Technology, Chapman University, CA, USA and is currently a Professor of Earth Systems Science and Remote Sensing and serves as the program director for the Computational and Data Sciences graduate program, Chapman University, CA, USA. He also holds a Full Professor position at Faculty of Science, Alexandria University, Egypt (on leave). His research interests include modeling and observations of earth systems' processes with focus on natural disasters. He has published more than 100 publications including peer reviewed papers, book chapters, full conference proceedings and other conference papers. He is a peer Reviewer for several international journals such as Atmospheric Chemistry and Physics, Remote Sensing, IEEE Transaction on Geosciences and Remote Sensing and others. His work has been funded by NASA, USDA, NSF and EU.

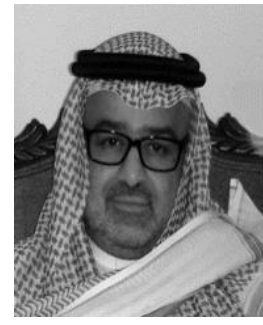

Mohammed Ali Qurban received the B.S degree in Aquatic Wealth Development from King Faisal University, Saudi Arabia, in 1988, and Master's degree in Marine Science from Florida Institute of Technology, USA, in 2000. He obtained his $\mathrm{Ph} . \mathrm{D}$ degree in Oceanography from the National Oceanography Center, University of Southampton, UK. Dr. Qurban has been an Assistant Professor at the Department of Geosciences, at CPG, KFUPM, since 2010. Currently he is also serving as the Director for Center for Environment and Water, Research Institute, KFUPM. His current research interests include Harmful Algal blooms, ocean acidification, and the effect of dust storms on the nutrient enrichment in the Arabian Gulf. He has received the Almarai Best Research Team award in 2017/2018. He has published over 36 publications which includes research articles in peerreviewed journals and in book chapters.

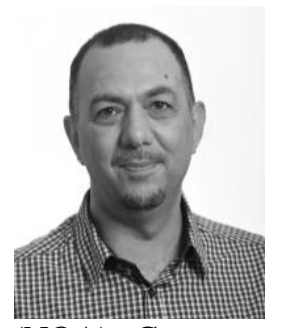

Vassilis Amiridis received the B.S. degree in Physics from the Aristotle University of Thessaloniki (AUTH), Greece, in 1998. He also received his M.S. and $\mathrm{PhD}$ degrees in Earth System Science and Atmospheric Physics from AUTH, Greece, in 2000 and 2006 respectively. Since 2006 he has been with the National Observatory of Athens (NOA), Greece, and is currently a Research Director at the NOA's Institute for Astronomy, Astrophysics, Space
Applications and Remote Sensing. His research interests focus on climate and the impact of atmospheric aerosols and clouds on radiation and extreme weather. The research is mainly based on advanced ground-based and space-borne remote sensing observations (passive and active remote sensing techniques) and theoretical models. He has published more than 90 publications in peer-reviewed scientific journals and his work received more than 2500 citations from third-party $(\mathrm{h}$-index $=$ 30, source: ISI Web of Knowledge). He is a member of the editorial board of EGU's Atmospheric Measurement Techniques Journal (Copernicus Publications, Impact Factor $=$ 3.2) and he is active reviewer in $~ 25$ scientific Journals in his field. His work has been funded by ESA and ERC.

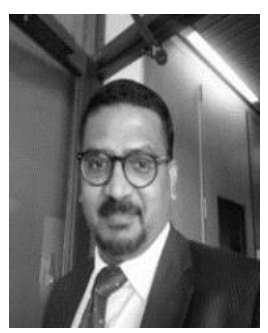

Manikandan received the B.S. degree in Zoology from Madurai Kamaraj University, India, in 1993, and Master's and $\mathrm{Ph}$. D degree in Marine Biology from Center of Advanced Study in Marine Biology, Annamalai University, India, in 1995 and 2006, respectively. He is one of the pioneers in perfecting the Hatchery Technology for the Mariculture of sea cucumbers and served as a Hatchery Manager for the Sea cuumber commercial Hatchery in Maldives from 1997 to 2000. In 2008, he joined the Center for Environment and Water, King Fahd University of Petroleum and Minerals, as Assistant Professor. His current research interests include Marine ecotoxicology, marine ecosystems, and marine contaminants including emerging contaminants. Dr. Manikandan is a member of ETMA, Saudi Arabia and has published more than 12 in peer-reviewed journals and five book chapters.

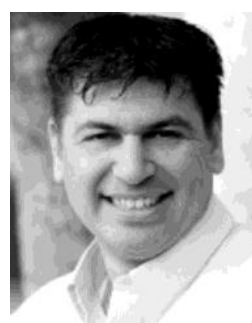

Michael J. Garay received the B.S. degree in physics and the B.A. degree in English literature from the University of Toledo, OH, USA, in 1995. He received the M.S. degree in atmospheric sciences from the University of California, Los Angeles, CA, USA, in 2004. He is currently a member of the Multi-angle Imaging SpectroRadiometer (MISR) science team at JPL working on aerosol and cloud retrievals. His work focuses on algorithm improvement, testing, validation, and the dissemination of scientific results from the MISR instrument. He is also working on tasks related to the Multiangle SpectroPolarimetric Imager, a successor to MISR being developed at JPL. These tasks involve polarized radiative transfer simulations, data visualization, and analysis. Previously, he worked on a number of projects at JPL including automatic image classification using support vector machines, multi-instrument and multiplatform data fusion, sensor webs, and feature identification and tracking. He has extensive experience with data visualization and analysis using a variety of satellite, airborne, and ground-based instruments. His research interests include 1$\mathrm{D}$ and 3-D polarized radiative transfer, satellite remote sensing of clouds and aerosols and related physical processes, multiinstrument data fusion and multi-platform sensor webs, 

HERE TO EDIT) <

machine learning techniques, and data analysis and visualization.

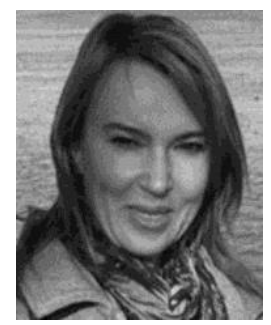

Olga V. Kalashnikova received the M.S. degree from the Physics Department, University of Colorado, Boulder, CO, USA, in 1997. She received the Ph.D. degree from the Department of Astrophysical, Planetary and Atmospheric Science (APAS), Boulder, CO, in 2002. She joined the Jet Propulsion Laboratory (JPL) in the fall of 2002 as a National Research Council Postdoctoral Scholar. During her postdoctoral years, she developed mineral dust optical models that later were incorporated into MISR operational aerosol retrievals. She is currently a JPL Scientist, and has over a decade of experience in the aerosol optical modeling and in studying atmospheric dust properties. Her career has focused on the aerosol microphysical and optical properties, aerosol remote sensing science, and applications of aerosols and their various effects on the Earth's radiation balance. As a science team member of MAIA and MISR instrument teams, she is working on projects to convert aerosol remote sensing data into information to help public health policy makers and officials make better decisions on the potential impact of climate change on human diseases and health conditions. Recently, she has expanded her research agenda into the area of polarimetry and the sensitivity of new polarimetric instruments to aerosols. She is an aerosol scientist actively participating in the algorithm development for the Multiangle Spectro-Polarimetric Imager (MSPI) Instrument.

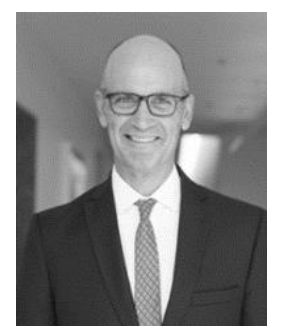

Thomas C. Piechota received the B.S. in Civil Engineering in 1989 from Northern Arizona University, his M.S. in Civil and Environmental Engineering in 1993 from UCLA, and his Ph.D. in Civil and Environmental Engineering in 1997 from UCLA. Dr. Piechota has been recognized for his efforts in teaching, research and as an administrator where he has helped advance the research enterprise through increases in research funding, outside partnerships and entrepreneurial activities. Dr. Piechota is the Vice President for Research and Professor of Environmental Science and Policy at Chapman University since 2016. In 2003, Dr. Piechota received a National Science Foundation CAREER Award for the project, "Improved Hydrologic Drought Forecasting Using Climate Information." From 2008-2013, Dr. Piechota was the Co-PI on a \$20 million National Science Foundation funded studies on climate change impacts in Nevada. Dr. Piechota was an invited Lead Author on the Southwest Chapter of the National Climate Assessment in 2013. Finally, Dr. Piechota was part of the 2013 Solar Decathlon team that took second place in world competition and first in the U.S. He has authored or coauthored more than 100 journal articles, book chapters, conference proceedings, and reports, and his work has been cited more than 3000 times. Dr. Piechota is a licensed Professional Engineer in the California. He has served on review panels for the National Science Foundation and various federal agencies. He has served on various professional and community committees including the American Society of Civil Engineers.

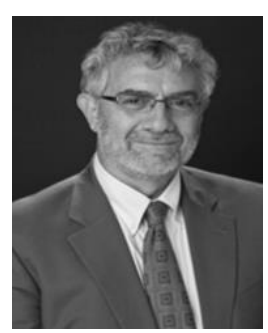

Daniele C. Struppa received the B.S. degree in Mathematics from the University of Milano, Italy, in 1977. He received his Ph.D. in Mathematics from the University of Maryland, College Park, in 1981, with a dissertation on exponential representations for solutions of systems of convolution equations. He has been an Assistant Professor at the University of Milano (1981-1984), at the Scuola Normale Superiore in Pisa (1984-1987), and then a Full Professor of Mathematics at the University of Calabria (1987-1994), at George Mason University (1988-2006), and now at Chapman University since 2006. He is currently the President of Chapman University, where he also holds The Donald Bren Distinguished Presidential Chair in Mathematics. He has published more than 200 publications including several books, edited books, peer reviewed papers, book chapters, full conference proceedings and other conference papers. A paper he coauthored in 2016 received the Cozzarelli Prize from the National Academy of Sciences. Dr. Struppa is a managing editor for Quantum Studies: Mathematics and Foundations, and for the Hypercomplex section of Complex Analysis: Operator Theory. He a reviewer for several international journals and his work has been funded by NATO, NSF and EU. 